\title{
LOS MARCADORES DE REFORMULACIÓN EN EL ESPAÑOL ORAL DE SANTIAGO DE CHILE: ANÁLISIS DISCURSIVO Y SOCIOLINGÜÍSTICO ${ }^{1}$
}

\author{
ABELARDO SAN MARTÍN NÚÑEZ \\ Universidad de Chile
}

\section{RESUMEN}

El objetivo de este artículo es analizar el empleo de los marcadores discursivos de reformulación en el español hablado en Santiago de Chile desde el punto de vista sociolingüístico. Específicamente, se describe el comportamiento de los marcadores del discurso, que cumplen la mencionada función, en una muestra estratificada de 120 entrevistas de hablantes santiaguinos y se establece la distribución sociolingüística de su empleo. Asimismo, se aplicó tanto el concepto y la clasificación de los marcadores del discurso de Martín Zorraquino y Portolés (1999) y Portolés (2001), como las sugerencias de Cortés (1998) y de Carbonero y Santana (2010) para el estudio cuantitativo de su variación social. En el análisis, se correlacionó el sexo, la edad y el grupo socioeconómico de los informantes con el empleo de los reformuladores, con base en su conmutabilidad funcional a nivel discursivo, según diferentes subtipos de reformulación (explicación, recapitulación, distanciamiento y rectificación). Los resultados del estudio muestran que los marcadores o sea, igual y al final, así como el subtipo de los reformuladores explicativos son los más frecuentes. Por último, la edad y el grupo socioeconómico de los sujetos son los factores más sensibles al empleo de las partículas relevadas.

PALABRAS CLAVE: marcadores del discurso, reformulación, variación discursiva, sociolingüistica, español de Chile.

\section{AbSTRACT}

The aim of this article is to analyze the use of the discourse markers of reformulation in Spanish spoken in Santiago, Chile, from a sociolinguistic point of

\footnotetext{
${ }^{1}$ La realización de este artículo contó con el apoyo del Concurso U-Apoya-Ayuda de Viaje de la Vicerrectoría de Investigación y Desarrollo de la Universidad de Chile. En este trabajo se sintetizan los resultados más relevantes de una de las secciones de nuestra tesis doctoral inédita, "Variación sintáctica y discursiva en el español hablado en Santiago de Chile. Análisis sociolingüístico del queísmo, el dequeísmo, el discurso referido y los marcadores de reformulación”, dirigida por el Dr. Humberto López Morales.
} 
view. Specifically, the behavior of discourse markers that meet this function is described and at the same time the sociolinguistics distribution of this use is established, in a stratified sample of 120 interviews. Also, the concept and the classification of discourse markers by Martín Zorraquino \& Portolés (1999) and Portolés (2001), and the suggestions of Cortés (1998) and Carbonero \& Santana (2010) for the quantitative study of social variation of markers is applied. In the analysis, sex, age and socioeconomic group of subjects interviewed were correlated with the use of reformulators, based on their functional commutability in discursive level, according to different subtypes of reformulation (explanation, recapitulation, detachment and correction). The results of the study show that markers o sea, igual y al final, and the explanatory reformulators are the most frequent. Finally, age and socioeconomic group of the participants are the most relevant variables in utilization of these markers.

KEYWORDS: discourse markers, reformulation, discursive variation, sociolinguistics, Chilean Spanish.

\section{INTRODUCCIÓN}

Los marcadores del discurso son unidades de procesamiento que cumplen una función extra-oracional a nivel semántico-pragmático, permitiéndole a los interlocutores controlar la situación de enunciación, organizar la información discursiva y guiar la interpretación de los enunciados (cf. Martín Zorraquino y Portolés, 1999 y Portolés, 2001). El interés por el estudio de estas unidades se ha incrementado de manera notable, en los últimos años, dando origen a un número significativo de estudios que dan cuenta de la importancia de estas partículas en la producción y la comprensión del discurso tanto oral como escrito (cf. Schiffrin, 1987 y 2003; Anscombre y Ducrot, 1994; Martín Zorraquino y Montolío, 1998; Martín Zorraquino y Portolés, 1999; Portolés, 2001 y Loureda y Acín, 2010, entre otros). No obstante, uno de los aspectos menos desarrollados en el marco de la investigación de los marcadores del discurso en lengua española es la dimensión dialectal y social de su empleo (Carbonero y Santana, 2010). El objetivo general de este trabajo -de naturaleza cuantitativa y correlacional- es analizar el comportamiento pragmático-discursivo y la estratificación sociolingüística de los marcadores de reformulación, en una muestra de 120 entrevistas realizadas a informantes santiaguinos. De manera consecuente, los objetivos específicos de nuestro estudio son:

a) identificar los marcadores que cumplen la función de reformulación en la muestra,

b) determinar su frecuencia de empleo $y$

c) correlacionar dichas frecuencias con las variables sociodemográficas: sexo, edad y grupo socioeconómico de los informantes. 
Asimismo, la hipótesis que someteremos a contrastación empírica en este trabajo es que los factores sociodemográficos de los sujetos inciden de manera irregular en el empleo de los reformuladores relevados en la muestra.

\section{Marco TeÓRICO}

\subsection{Los marcadores del discurso desde el punto de vista sociolingüistico}

Nuestra pesquisa se enmarca en las directrices teóricas y metodológicas generales de la sociolingüística variacionista desarrollada por Labov (1983), con las necesarias adaptaciones al estudio de la variación en el ámbito discursivo (Macaulay, 2003) ${ }^{2}$. Los estudios en el ámbito del variacionismo han demostrado, en general, la influencia de factores sociales como el sexo, la edad, el nivel educacional o el grupo socioeconómico de los hablantes, en conjunto con la de factores internos, en el comportamiento lingüístico (Bright, 1998; Silva Corvalán, 2001; López Morales, 2004; Blas Arroyo, 2005; Moreno Fernández, 2009 y Serrano, 2011). Silva-Corvalán, en este sentido, señala que "la variación lingüística no es aleatoria sino que está condicionada tanto por factores internos al sistema de la lengua como por factores sociales externos a ella" (2001: 2). Según este principio, la variación sociolingüística ha sido definida como "la alternancia de dos o más expresiones de un mismo elemento, cuando ésta no supone ningún tipo de alteración o cambio de naturaleza semántica y cuando se ve condicionada por factores lingüísticos y sociales" (Moreno Fernández, 2009: 39). No obstante, la extensión del concepto de variable sociolingüística al estudio de fenómenos más allá del nivel fonético planteó una serie de dificultades, especialmente a partir del trabajo de Lavandera (1978), donde se cuestionó explícitamente dicha extensión, arguyendo que no estaba garantizado en el estudio de las mencionadas variables el principio de invariabilidad a nivel semántico. A pesar de las diferentes posturas en torno a este debate, en principio, la variación lingüística "definida como el uso alterno de formas diferentes de decir lo mismo, se puede encontrar prácticamente en todos los niveles de la lengua, desde el más concreto (fonético-fonológico) al más amplio (discurso, por ejemplo), pasando por la gramática y el léxico" (Moreno Fernández, 2009: 22).

2 Para este autor, el variacionismo ha tendido a cuantificar más los fenómenos fonológicos o los morfológicos, debido a que el estudio del discurso oral requiere, por lo general, muestras más grandes de lenguaje en uso, así como asumir decisiones metodológicas que no son tan cruciales en el estudio de otros tipos de variación (Macaulay, 2003: 284). En suma, la tarea de analizar la variación discursiva es, quizás, más compleja que la de estudiar otros tipos de variación, lo que redunda en que los estudios sobre variacionismo discursivo no sean tan abundantes. 
En relación con el problema que nos ocupa, Cortés (1998: 160) concluye que el estudio variacionista de los marcadores es posible, si se cumple el requisito de contrastar las frecuencias de conectores que cumplan las mismas funciones, lo que trae aparejadas no pocas dificultades. Según este autor, pese a las limitaciones que se ha impuesto al estudio variacionista de los marcadores del discurso, la variabilidad de los mismos no está bajo cuestionamiento puesto que:

Toda elección de un marcador, como la de cualquier otro fenómeno fónico, gramatical o léxico, puede venir condicionada bien por una serie de circunstancias estilísticas -registros más o menos formales-, bien por la pertenencia del hablante a un determinado grupo sociocultural -nivel de cultura, edad, sexo-, bien por la modalidad -oral, escrita-, etc. (Cortés, 1998: 152).

Por lo tanto, para el análisis sociolingüístico de los marcadores, es preciso que se asocien las características de los informantes con aquellas partículas que desempeñen una función común en el discurso (Cortés, 1998: 154). Por su parte, Carbonero y Santana (2010: 516-517) señalan la carencia de trabajos que aborden la variación espacial y social de los marcadores del discurso, aunque -al mismo tiempo- destacan el interés de esta línea de trabajo para el mejor conocimiento de estas unidades de procesamiento. Como en trabajos anteriores (San Martín, 2004-2005, 2011 y 2013 y Rojas et al., 2012), sugerimos la posibilidad de aplicar el concepto de "variable lingüística" -en un sentido amplio- al estudio de los marcadores del discurso. De acuerdo con nuestra perspectiva, una vez identificadas las partículas que cumplan una función pragmática equivalente, la aplicación del concepto de variable sociolingüística al estudio de los marcadores del discurso es factible, "puesto que este tipo de formas parece cumplir con las condiciones propuestas en el marco del variacionismo, es decir, consistir en "formas alternativas de decir lo mismo"” (San Martín, 2004-2005: 213).

\subsection{Los marcadores de reformulación en la lengua española}

Los marcadores del discurso son unidades lingüísticas de enlace de carácter invariable, que no ejercen una función sintáctica a nivel oracional y cuya función primordial es orientar las inferencias que se realizan en la comunicación (Portolés, 2001: 25-26) ${ }^{3}$. Para el presente estudio, adoptare-

\footnotetext{
${ }^{3}$ Martín Zorraquino (1998: 35-51) plantea que, pese a la heterogeneidad de los marcadores del discurso, relativa tanto a las categorías a las que pertenecen como a su distribución en el discurso y a sus funciones pragmáticas, dichas unidades presentan, entre otras, las si-
} 
mos, principalmente, la perspectiva teórica sobre los marcadores del discurso de Martín Zorraquino y Portolés (1999) y Portolés (2001). Desde dicha perspectiva, los marcadores de reformulación "presentan el miembro del discurso que introducen como una nueva formulación de un miembro anterior" (Martín Zorraquino y Portolés, 1999: 4121) ${ }^{4}$. De acuerdo con su función discursiva específica, los reformuladores pueden clasificarse en cuatro grupos (adaptado de Martín Zorraquino y Portolés, 1999: 4122 y siguientes):

1) explicativos: presentan el miembro del discurso que introducen como una reformulación que aclara o explica lo que se ha querido decir en otro miembro anterior que pudiera ser poco comprensible, por ejemplo, o sea, es decir, esto es y a saber.

2) rectificativos: sustituyen un primer miembro, que presentan como una formulación incorrecta, por otra que la corrige o, al menos, la mejora, por ejemplo, mejor dicho, más bien y digo.

3) de distanciamiento: presentan como no relevante un miembro del discurso anterior, al mismo tiempo que muestran la nueva formulación como aquella que condicionará la prosecución del discurso, anulando la pertinencia de dicho miembro, por ejemplo, en cualquier caso, en todo caso, de todos modos, de todas formas, de todas maneras, de cualquier modo, de cualquier forma y de cualquier manera.

4) recapitulativos: muestran al miembro del discurso en el cual se insertan como una conclusión o recapitulación a partir de un miembro anterior o una serie de ellos, conservando la misma orientación argumentativa de los miembros anteriores -por ejemplo, en suma, en conclusión, en resumen y en síntesis- o incorporando miembros con una orientación opuesta -por ejemplo, en resumidas cuentas, en definitiva, en fin, total, vamos, al fin y al cabo y después de todo-.

Cortés y Camacho (2005: 200), por otro lado, señalan que los reformuladores son marcadores de relación jerárquica unidireccional, puesto que el segmento reformulador es más importante que el anterior y existe una yuxtaposición entre ambos segmentos. En este sentido, el segmento refor-

guientes propiedades comunes: a) no pueden ser sustituidas por elementos pronominales o deícticos, b) no pueden ser sometidos a interrogación parcial, c) no admiten la coordinación con elementos equifuncionales y d) no pueden ser reemplazados por elementos pronominales que reproduzcan la totalidad, o la parcialidad, de la oración en la que se sitúan.

${ }^{4}$ En relación con el concepto y las características de los marcadores de reformulación, cabe destacar que los primeros estudios sobre la reformulación son los de Gülich y Kotschi (1983), Roulet (1987) y Rossari (1994), para el francés, y Blakemore (1993), para el inglés. En español, son importantes los trabajos de Casado Velarde (1991), Martín Zorraquino y Portolés (1999), Portolés (2001), Garcés Gómez (2003, 2005, 2008, 2010 y 2011) y Fuentes (2009). Desde un punto de vista contrastivo en inglés, español y catalán los reformuladores son estudiados por Cuenca (2003). 
mulado no es necesario para comprender el segmento reformulador, ya que el primero está contenido en el segundo. Dicha característica sería distintiva de los reformuladores, es decir, los distingue de otros tipos de marcadores. Por su parte, Garcés (2003 y 2011) destaca que la reformulación es un "procedimiento de organización del discurso que permite al hablante volver sobre un segmento anterior para reinterpretarlo y presentarlo de manera distinta" (2011: 90), que responde a cinco motivaciones de los hablantes: explicar, recapitular, reconsiderar, distanciarse o corregir (2003: 114). Aplicando los supuestos de la lingüística textual de Gülich y Kotschi (1983 y 1995) y Rossari (1994), además, Garcés (2003 y 2011) distingue entre la reformulación parafrástica, en la que se plantea una equiparación semántica y pragmática entre los segmentos reformulado y reformulador, y la no parafrástica, en la que se propone un distanciamiento de diferente grado (mínimo, medio y máximo) entre ambos segmentos. Así, para esta autora, la reformulación es un "proceso de reinterpretación de un segmento previo, explícito o implícito, que, según la relación entre los miembros y el tipo de marcador empleado, puede ir desde la equivalencia hasta el distanciamiento" (Garcés, 2008: 82) ${ }^{5}$. Su clasificación considera cinco tipos de marcadores de reformulación, de acuerdo con las motivaciones señaladas más arriba: explicación, rectificación, recapitulación, reconsideración y separación (Garcés, 2008: 86).

Por lo que refiere al español de Chile, en Rojas et al. (2012) se estudian los marcadores de reformulación empleados en una muestra de 72 hablantes santiaguinos, de acuerdo con los siguientes tipos específicos de reformuladores: explicativos, de distanciamiento, recapitulativos y rectificativos. Los resultados muestran un empleo preponderante de o sea, tanto con valor explicativo como rectificativo, de igual como reformulador de distanciamiento y de al final con función recapitulativa. Además, los factores edad y grupo socioeconómico de los hablantes son más determinantes en el empleo variable de los marcadores relevados. Por otro lado, en su relevamiento de los marcadores del discurso empleados en 12 entrevistas de la norma culta santiaguina, Valencia (2014b) señala que los reformuladores constituyen el tipo de marcador de discurso menos utilizado en ambas sub-muestras analizadas (11\% y $12 \%$, respectivamente), entre los

\footnotetext{
${ }^{5}$ Según Garcés (2008: 67), la capacidad de replantear enunciados previos mediante otros que nos parecen más expresivos o adecuados para nuestra propia intención es una propiedad de la competencia metapragmática de los hablantes. Este aspecto también ha sido destacado por Portolés (2004), quien señala que la capacidad metalingüística o metapragmática para representarnos estados mentales de nuestros interlocutores es aplicable al caso de la reformulación, puesto que, en ocasiones, los hablantes pueden llegar a considerar que lo que han dicho (su formulación) ha sido poco acertado, proponiendo entonces una nueva forma de decirlo (una reformulación). De esta manera, según Loureda (2001), cada reformulación es una reflexión metalingüística (Portolés, 2004: 37).
} 
que destacan los explicativos, en particular, o sea con una altísima frecuencia. También se recogieron ejemplos de los explicativos es decir y en otras palabras, pero con porcentajes de ocurrencia inferiores. De igual manera, se hallaron ejemplos de los recapitulativos en fin, en definitiva y total. Solo se encontraron casos de más bien como reformulador de rectificación y de en todo caso como marcador de distanciamiento ${ }^{6}$.

\section{Metodología}

\subsection{Corpus}

El corpus que servirá de base para nuestro estudio corresponde a 120 entrevistas sociolingüísticas pertenecientes al corpus del grupo de Estudio Sociolingüístico del Español de Chile (ESECH) ${ }^{7}$. Las entrevistas fueron realizadas a hablantes santiaguinos, entre 2005 y 2011, por los estudiantes en la asignatura de Sociolingüística de los programas de Licenciatura en Lengua y Literatura Hispánicas y Licenciatura en Lengua y Literatura Inglesas de la Universidad de Chile. En la situación de entrevista, los entrevistadores debían tratar de superar la "paradoja del observador" consiguiendo, de esta forma, una muestra significativa de discurso natural grabado (estilo vernáculo) de hablantes representativos de la comunidad de habla en estudio (Labov, 1983). El número de entrevistas antes indicado totaliza, aproximadamente, 116 horas de grabación, cuya transcripción fue exhaustivamente revisada, sin exclusión de ninguna de las secciones del instrumento.

\subsection{Población y muestra}

En nuestra investigación se consideró la población constituida por hombres y mujeres de la Región Metropolitana de más de 20 años de $\operatorname{edad}^{8}$. El

\footnotetext{
${ }^{6}$ No obstante, es importante precisar que la misma autora declara que, debido a motivaciones contrastivas, en su estudio no se relevaron usos idiosincrásicos o dialectales (Valencia, 2014a: 7-8). Por lo tanto, su análisis solo se limitó a identificar el empleo del inventario de marcadores informado en Martín Zorraquino y Portolés (1999). Esto plantea una diferencia de estrategia de indagación fundamental con respecto a la adoptada en el presente trabajo.

7 El ESECH es un grupo de investigación del Departamento de Lingüística de la Facultad de Filosofía y Humanidades de la Universidad de Chile coordinado por nosotros.

${ }^{8}$ Por lo que refiere a los criterios de asignación de estatus de hablante nativo de Santiago de Chile, hemos adaptado la propuesta de Prieto (1995-1996), por lo que se aplicaron las siguientes restricciones en la selección de los sujetos: 1) haber nacido y residido en forma ininterrumpida en Santiago, 2) haber nacido y residido en Santiago la mayor parte de sus vidas, salvo por periodos que sumados no superen los cinco años y 3 ) haber residido en forma ininterrumpida en Santiago desde los cinco años de edad.
} 
cuestionario se aplicó a una muestra del tipo "muestra por cuotas con afijación uniforme", en la que se divide a la población en estratos o categorías y se asigna una cuota a cada uno de los distintos estratos (López Morales, 1994: 58). Por lo que respecta al tamaño de la muestra, hemos optado por conformarla con un número de informantes considerado, en general, como suficiente en la bibliografía sociolingüística (cf. Trudgill y Hernández Campoy, 2007, s. v. representatividad y López Morales, 1994: 52). La muestra, así conformada, comprende un total de 120 entrevistas realizadas a igual número de sujetos, distribuidos como se indica en la Tabla 1 que mostramos a continuación:

TABLA 1. Proporción de sujetos según características sociodemográficas de sexo, edad y grupo socioeconómico

\begin{tabular}{|l|r|r|r|r|r|r|c|}
\cline { 2 - 8 } \multicolumn{1}{c|}{} & \multicolumn{2}{c|}{$20-34$} & \multicolumn{2}{c|}{$35-54$} & \multicolumn{2}{c|}{55 y más } & \multirow{1}{*}{} \\
\cline { 2 - 8 } \multicolumn{1}{c|}{} & $\mathrm{H}$ & $\mathrm{M}$ & $\mathrm{H}$ & $\mathrm{M}$ & $\mathrm{H}$ & $\mathrm{M}$ & Total \\
\hline Medio alto & 5 & 5 & 5 & 5 & 5 & 5 & $=30$ \\
\hline Medio & 5 & 5 & 5 & 5 & 5 & 5 & $=30$ \\
\hline Medio bajo & 5 & 5 & 5 & 5 & 5 & 5 & $=30$ \\
\hline Bajo & 5 & 5 & 5 & 5 & 5 & 5 & $=30$ \\
\hline & 20 & 20 & 20 & 20 & 20 & 20 & $=120$ \\
\hline
\end{tabular}

\subsection{Procedimiento de estratificación social utilizado en ESECH}

Para la estratificación de los sujetos que conforman la muestra del estudio, se empleó el sistema de adscripción de estatus social empleado en ESECH que se basa en la asignación del puntaje -que se indica entre paréntesis- a los informantes, de acuerdo con las siguientes variables:

a) nivel educacional (3),

b) profesión u ocupación (2) y

c) comuna de residencia (1).

La explicación en detalle de dichas variables se encuentra en Prieto (1995-1996), cuya propuesta fue perfeccionada y actualizada con base en los estudios acerca de la realidad socioeconómica chilena de la empresa de Investigaciones de Mercado y Opinión Pública (ADIMARK, 2003), la Descripción Básica de los Niveles Sociales realizada por el Instituto Consultor en Comercialización y Mercado (ICCOM, 2005) y la propuesta de estratifi- 
cación de la Asociación de Investigadores de Mercado (AIM, 2008) ${ }^{9}$. A partir de la asignación de los mencionados puntajes, se distinguieron cuatro grupos socioeconómicos, definidos según los rangos siguientes

a) Medio alto (MA): 42-36,

b) Medio (M): 35-27,

c) Medio bajo (MB): 26-18 y

d) Bajo (B): $17-6^{10}$.

El intervalo de cada rango responde a la mayor coincidencia con los puntajes que han establecido los estudios sociológicos y de mercado para la clasificación de estratos socioeconómicos, aunque con las debidas adaptaciones, puesto que en esta muestra no se incluyen ni el grupo de la extrema pobreza ni el de la extrema riqueza (cf. San Martín y Guerrero, 2015).

\subsection{Procedimiento analítico}

Nuestro análisis de la función discursiva "reformulación mediante marcadores" se concentró en la determinación de las frecuencias de ocurrencia de cada una de las partículas específicas, que la cumplen en las entrevistas que conforman la muestra recopilada. Asimismo, de modo coherente con nuestros objetivos, se observará la incidencia de los siguientes factores sociodemográficos de los hablantes: sexo, edad y grupo socioeconómico. Por lo que se refiere a la descripción de los procedimientos estadísticos aplicados, en este trabajo seguimos las sugerencias e indicaciones de Moreno Fernández (1990), López Morales (1994) y Hernández Campoy y Almeida (2005). El análisis estadístico atenderá a dos niveles de observación:

a) en términos descriptivos, según las frecuencias absolutas y los porcentajes de frecuencia de cada reformulador y

b) en términos interpretativos o inferenciales, con base en la comparación entre las medias o tendencias centrales de los marcadores más frecuentes, esto es, de aquellos con más de 25 ocurrencias.

\footnotetext{
${ }^{9}$ Cabe precisar que el modelo de nivel socioeconómico fue adaptado de estos estudios de mercado en función de los objetivos que se propone el grupo ESECH, que busca definir un perfil más bien sociocultural de la comunidad lingüística en estudio. En consideración a esto, para la estratificación socioeconómica, una de las variables más determinantes fue el nivel educacional y, por esta razón, es la que asigna el mayor puntaje. Asimismo, el nivel de ingresos demuestra muy poca relevancia para los estudios de mercado antes mencionados, por ello no fue considerado en la determinación de los perfiles socioeconómicos.

${ }^{10}$ En la selección de las entrevistas del corpus se cauteló la consistencia entre las variables antes mencionadas de manera que respondieran a lo que Prieto (1995-1996), siguiendo a Lenski (1954), denominara como congruencia de estatus.
} 
El paquete estadístico al que hemos recurrido para la estadística inferencial es el SPSS (Statistical Package for the Social Sciences), versión 15.0 para Windows, específicamente, la prueba Análisis de varianza ANOVA. En atención a que la distribución de los datos, en algunos casos, pudiera ser anormal, se complementará dicho análisis con su análogo de tipo no paramétrico, esto es, Anova de Kruskal Wallis. En ambos casos, el grado de significación se definirá en el $5 \%$, según el cual p $=<0,05$ será estadísticamente significativo.

\section{ANÁlisIS}

En nuestro corpus se identificaron 4427 casos de alternancia de la función variable a nivel de discurso: "reformulación de un segmento discursivo previo mediante marcadores". En términos generales, las partículas relevadas se distribuyen en los siguientes tipos de marcadores de reformulación con las frecuencias absolutas y los porcentajes que se indican:
a) explicativos $(2403 / 4427=54,3 \%)$,
b) recapitulativos $(412 / 4427=9,3 \%)$,
c) de distanciamiento $(1356 / 4427=30,6 \%)$ y
d) rectificativos $(256 / 4427=5,8 \%)$.

GRÁfICO 1. Porcentaje de frecuencia de los tipos de marcadores de reformulación relevados en el corpus

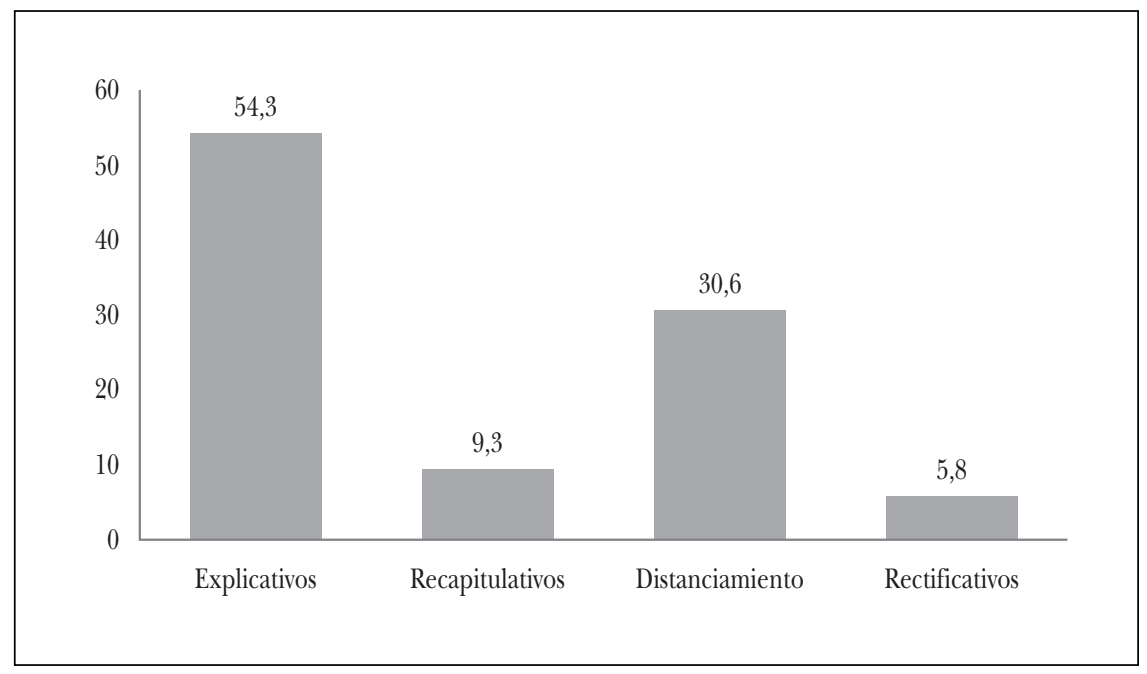


En conclusión, en la muestra analizada, la frecuencia de los marcadores de reformulación explicativa es mayoritaria, en términos porcentuales, seguida de los reformuladores de distanciamiento, tal como puede apreciarse en el Gráfico 1.

El predominio de los reformuladores explicativos, seguido del de los de distanciamiento, contrasta con las bajas frecuencias de ocurrencia de los reformuladores recapitulativos y rectificativos. Lo anterior implica que la explicación y el distanciamiento, pero no la recapitulación y la rectificación, constituyen las funciones predominantes dentro de la reformulación introducida mediante marcadores, en la muestra analizada.

Por otro lado, la Tabla 2 (en la página siguiente) presenta la frecuencia absoluta y porcentual de los marcadores de reformulación específicos recogidos en el corpus, ordenados de mayor a menor.

Como puede apreciarse en la Tabla 2, en términos de frecuencias absolutas y porcentuales, más de la mitad de las instancias de reformulación mediante partículas discursivas en la muestra corresponde al empleo del marcador explicativo o sea. Le sigue en importancia igual como reformulador de distanciamiento, aunque 20 puntos porcentuales más abajo. Luego aparecen o sea como marcador rectificativo, el reformulador recapitulativo al final y o sea con función recapitulativa, en el rango de frecuencia superior al centenar de casos. Por último, entre los marcadores que muestran un empleo mayor a 25 ocurrencias, están digamos y onda como marcadores explicativos, los reformuladores de distanciamiento en todo caso y de todas maneras, así como bueno como marcador rectificativo. El resto de los marcadores de reformulación de la tabla ostenta frecuencias muy inferiores, incluso, a nivel de casos únicos.

Cabe destacar que las partículas relevadas se comportan como unidades lingüísticas invariables y sintácticamente periféricas, cuya función primordial es orientar las inferencias que se realizan en el discurso, por lo tanto, se adecúan al concepto de marcador del discurso (Martín Zorraquino y Portolés, 1999 y Portolés, 2001). De igual modo, como ilustraremos más adelante, mediante su empleo los hablantes efectúan un movimiento retroactivo que les permite volver sobre un enunciado anterior para presentarlo de otra manera, con el propósito de facilitar una interpretación adecuada por parte del interlocutor; en consecuencia, corresponden al subtipo de los marcadores de reformulación (Garcés, 2003 y 2011). En términos generales, en nuestros materiales se comprobó la incidencia de las categorías analíticas propuestas por Martín Zorraquino y Portolés (1999), Portolés (2001) y Garcés (2003 y 2011) para el estudio de este tipo de marcadores ${ }^{11}$.

11 No obstante, no distinguimos, como propone Garcés (2003 y 2011), entre reformuladores de recapitulación y reconsideración. En dicha distinción funcional, la autora, siguiendo 
TABLA 2. Frecuencia absoluta y porcentaje de los marcadores de reformulación relevados en el corpus

\begin{tabular}{|c|c|c|}
\hline Marcador de reformulación & Frecuencia absoluta & Porcentaje de frecuencia \\
\hline o sea explicativo & 2217 & 50,08 \\
\hline igual & 1300 & 29,37 \\
\hline o sea rectificativo & 200 & 4,51 \\
\hline al final & 184 & 4,16 \\
\hline o sea recapitulativo & 134 & 3,02 \\
\hline digamos explicativo & 92 & 2,08 \\
\hline onda & 55 & 1,24 \\
\hline en todo caso & 30 & 0,68 \\
\hline bueno & 29 & 0,66 \\
\hline de todas maneras & 26 & 0,59 \\
\hline es decir explicativo & 21 & 0,47 \\
\hline en fin & 20 & 0,45 \\
\hline total & 19 & 0,43 \\
\hline porser & 17 & 0,38 \\
\hline en definitiva & 17 & 0,38 \\
\hline a las finales & 15 & 0,33 \\
\hline digamos rectificativo & 7 & 0,16 \\
\hline digo & 7 & 0,16 \\
\hline al final y al cabo & 6 & 0,14 \\
\hline al final al cabo & 6 & 0,14 \\
\hline miento & 6 & 0,14 \\
\hline más bien & 4 & 0,09 \\
\hline a la final & 3 & 0,07 \\
\hline al final de cuentas & 2 & 0,05 \\
\hline cuento corto & 2 & 0,05 \\
\hline perdón & 2 & 0,05 \\
\hline a fin de cuentas & 1 & 0,02 \\
\hline al fin y al cabo & 1 & 0,02 \\
\hline a la final y al cabo & 1 & 0,02 \\
\hline en resumen & 1 & 0,02 \\
\hline es decir rectificativo & 1 & 0,02 \\
\hline vale decir & 1 & 0,02 \\
\hline Total & 4427 & 100 \\
\hline
\end{tabular}


Asimismo, como se indica en la Tabla 2, tres de los 32 marcadores identificados en el paradigma de reformuladores cumplen más de una función, dentro de la reformulación como función variable general, de acuerdo con sus distintos contextos de empleo: o sea, digamos y es decir. De esta manera, o sea, descrito típicamente como un reformulador explicativo (Portolés, 2001), puede adquirir otros valores funcionales como rectificativo y recapitulativo. Asimismo, digamos y es decir pueden funcionar, más allá de su valor reformulador explicativo, como rectificativos, si bien el primero de estos valores es más prototípico para ambos marcadores. Como señalamos en Rojas et al. (2012), podríamos encontrar una explicación a la polifuncionalidad de $o$ sea en el hecho de que se trata, por lejos, del reformulador más frecuente en la muestra analizada. Por otro lado, hemos verificado la presencia de marcadores, con función reformuladora, que -en generalno han sido considerados como tales por los autores antes citados como igual, onda, por ser, a la final, a las finales, miento, cuento corto y perdón. Solo en el caso de igual, su función como reformulador de distanciamiento ha sido destacada por San Martín (2004-2005 y 2013) para el español de Chile $^{12}$ y, más recientemente, por García y Marcovecchio (2013) para el de Argentina.

\subsection{Análisis discursivo de los marcadores de reformulación relevados en el corpus}

En este apartado, se presentará el análisis discursivo de los tipos de marcadores de reformulación identificados en nuestros materiales. El empleo de un marcador de reformulación implica un movimiento retroactivo sobre un segmento discursivo anterior para reinterpretarlo y presentarlo de manera distinta, lo que puede ser representado mediante el siguiente esquema:

Reformuladores: replantean o reiteran (movimiento retroactivo)

Segmento reformulado $\leftarrow$ Segmento reformulador

$$
\mathrm{A} 1 \leftarrow \mathrm{A} 2
$$

\footnotetext{
a Gülich y Kotschi (1995), plantea diferentes grados de separación entre los enunciados, lo que determinaría la existencia de tres tipos de reformulación no parafrástica: a) recapitulación (mínimo), b) reconsideración (medio) y c) distanciamiento (máximo). Aunque el argumento de una diferenciación gradual entre los tipos de reformulación nos parece pertinente, como veremos más adelante, en nuestros materiales, no se identificaron ejemplos que permitieran sostener la distinción entre recapitulación y reconsideración.

${ }^{12}$ También en Hummel (2012) se estudia la polifuncionalidad de igual como adjetivo y marcador del discurso, mientras que en Fant (2011) se analiza su valor concesivo como modalizador, ambos en materiales del español de Chile.
} 
En este sentido, los reformuladores presentan el miembro del discurso que introducen como la nueva perspectiva desde la que se debe reinterpretar un primer miembro. Las funciones de los reformuladores del discurso, por lo tanto, son:

1) introducir una nueva formulación y

2) reelaborar una idea anterior.

A su vez, estas funciones tienen como objetivo:

a) facilitar la compresión del oyente o

b) ampliar la información previa.

A continuación, se explican e ilustran los tipos de marcadores de reformulación verificados en el corpus de la presente pesquisa ${ }^{13}$. Para facilitar la comprensión de cada categoría, hemos incluido, además del paradigma de reformuladores y de los ejemplos correspondientes, un esquema aclaratorio que representa el movimiento retroactivo subyacente a cada tipo de reformulación mediante marcadores relevado. Las definiciones de cada tipo de marcador de reformulación corresponden a las propuestas por Martín Zorraquino y Portolés (1999) y que son reseñadas más arriba (cf. 1. 2).

1) Explicativos: introducen un miembro del discurso que amplía la información anterior, especificando su contenido, a efecto de asegurar la comprensión de lo dicho. Los reformuladores que cumplieron la función explicativa en nuestro corpus, en orden de importancia, fueron o sea, digamos, onda, es decir, por ser y vale decir.

\section{Explicativos: aclaran

$$
\mathrm{A} 1 \leftarrow=\mathrm{A} 2
$$

\section{Ejemplos ${ }^{14}$ :}

${ }^{13}$ En otro lugar, esperamos presentar, con mayor detalle, los resultados del estudio de cada tipo específico de marcador de reformulación, incluido en nuestra tesis doctoral. Aquí nos interesa, más bien, presentar los hallazgos relativos al contraste entre los tipos generales de reformulación mediante marcadores. Por supuesto, no se incluyen en el presente análisis otros valores discursivos de las partículas relevadas, que se apartan de la noción de reformulación, pero que sí fueron identificados en el procesamiento del corpus. Entre dichas funciones, destacan el empleo como introductor de respuesta de bueno y o sea, de ejemplos de onda y por ser y de discurso directo de o sea y onda, así como el valor continuativo de digamos, por ser y bueno, modalizador de o sea y enfático de de todas maneras.

14 Respecto de la transcripción de los ejemplos, es necesario señalar las siguientes convenciones gráficas: 1) cuando corresponda a ejemplos de mayor extensión, $\mathrm{E}=$ entrevistador e I = informante; 2) como se trata de variables no fonéticas y, por lo tanto, la pronunciación no es el foco de nuestro análisis, el texto correspondiente a cada ejemplo se transcribe en 
(1) es una persona muy/ lo encuentro muy carismático/ o sea/ tiene/ por presencia el tipo es muy simpático muy agradable más encima tiene una estupenda señora/ una estupenda familia/ o sea es como el sueño del pibe/ como dicen los argentinos// o sea/ creo que cumple con todas las condiciones/y le va a ir súper bien (MAIIIH180),

(2) y uno tampoco los puede tener encerrados en una burbuja/ o sea esta es la vida/ y y va a depender también de los grados de vinculación que tú tengas con ellos/ o sea cómo se conversa en la familia/ qué temas se conversan/ qué confianza tú les das a ellos (MIIM121),

(3) dada la razón que figuro yo con la enseñanza básica solamente $o$ sea de primero a sexto/ es que después mis padres me matriculaban en colegios y cuando ellos iban a saber de/ cómo me iba en la escuela/ yo ya no estaba en ese colegio yo estaba en otro que me había cambiado yo solo (BIIIH035),

(4) la farándula es lo que es nomás po// es vivir del del comentario de las otras personas y y figurar por ese tipo de cosas/ ¿quién anda con quién? ¿quién se operó qué cosa? / eso me parece que es algo ridículo que que/ bueno es entretenido da/ digamos que sazona un poco el ambiente pero hay gente que se queda pegada o que vive de eso lo hallo pa/ penoso (MIIM122),

(5) mis papás generalmente se quedan en la casa/ y si no se quedan/ y si/ y a veces ee/ hacen como un happy hour/ onda se toman un vinito/y unos quesitos/y/ carne y cosas así (MAIM155),

(6) mi pega entonces/tiene que ver con el área social específicamente/ con los programas/ que la municipalidad tiene/ es decir/ adulto mayor/ deportes/ mujeres secretaría de la juventud/ gestión comunitaria (MAIIM170),

(7) porque los demás equipos ya sea Argentina/ Brasil/ tienen gente ya que ya son son son mayores/ no son con la edad por ser estos

ortografía convencional, incluidos los acentos gráficos; 3) con el propósito de no desnaturalizar demasiado la representación del habla chilena, se ha conservado la manifestación gráfica de determinados usos característicos del español hablado en Chile, como el uso del voseo paradigmático con elisión de $-s$, por ejemplo, estái, soi, viví (estáis, sois, vivís con valor de segunda persona del singular, tú) y el empleo de marcadores del discurso, como ¿cachái? (“¿entiendes?”) y po (pues); 4) para la mejor comprensión de los ejemplos incluidos en este estudio, se ha suprimido el sistema de etiquetas pertenecientes al Standard Generalized Markup Language (SGML) contenidas en el Text Encoding Initiative (TEI), que se emplea en la transcripción de las entrevistas de ESECH, excepto las pausas que se señalan con /. Al final de cada ejemplo, se indica, entre paréntesis, el código del informante, según las siguientes convenciones: grupo socioeconómico ( $\mathrm{MA}=$ medio alto, $\mathrm{M}=$ medio, $\mathrm{MB}=$ medio bajo, $\mathrm{B}=$ bajo), grupo etario (III = adultos mayores de 55 años y más, II = sujetos adultos de edad intermedia entre 35 y 54 años y $\mathrm{I}=$ hablantes jóvenes de entre 20 y 34 años $)$ y sexo $(\mathrm{M}=$ mujer y $\mathrm{H}=$ hombre $)$. A continuación del sexo se señala el número correlativo del sujeto en el corpus. 
que son de veintidós por ser el equipo chileno parece que el mayor de todos tendrá veintisiete veintiocho años/ y y de ahí para abajo (MBIIIH083),

(8) básicamente información para atender a los clientes/ y/ procedimientos/ cómo atender a los clientes/y protocolo de a/ de atención/ vale decir qué se les dice a los clientes (MAIIH161).

2) Recapitulativos: introducen un segmento discursivo a modo de síntesis, que compendia lo dicho con anterioridad, también con valor conclusivo. Los marcadores recapitulativos recogidos en la muestra, según su frecuencia, fueron al final, o sea, en fin, total, en definitiva, a las finales, al final y al cabo, al final al cabo, a la final, al final de cuentas, cuento corto, a fin de cuentas, al fin y al cabo, a la final y al cabo y en resumen.

$$
\begin{gathered}
\text { Recapitulativos: resumen } \\
\mathrm{A} 1+\mathrm{A} 2+\mathrm{A} 3 \leftarrow=\mathrm{A} 4
\end{gathered}
$$

Ejemplos:

(9) yo he tratado de no endeudarme de de no ir a las casas comerciales/ y si tengo que comprar algo/ comprarlo al contado/ si es que tengo el dinero/ lo compro al contado entonces así ya he dese/ yo he ido desechando varias tarjetas de crédito que yo no las uso porque es muy excesivo el cobro de la mantención/ te cobran la mantención/ te cobran por ejemplo seguro de desgravamen/ y eso al final se va sumando a la cuenta/ al final terminái pagando un ojo de la cara entonces yo eso es lo que he hecho/ trato de/ de no endeudarme en la casas comerciales (MBIIIM089),

(10) pero tení en la medianía una cantidad de colegios particulares subvencionados que son pésimos/ donde los sostenedores se preocupan de ganar plata/ donde los colegios tienen malas condiciones y los cabros al final terminan entrando al mismo círculo de endeudarse después para entrar a la universidad/ una cuestión privada (MAIH145),

(11) yo creo que los fundamentos teóricos son son los correctos/ pero la aplicación en términos de definir los recorridos y la frecuencia/ y los/ y el número de transbordos/ ee/ hay un error de implementación po/o sea/ ee/ hay/ tienen que revisar más la malla de/ de recorridos/y lo otro que un aspecto negativo// que yo no entiendo cómo antes los empresarios microbuseros ganaban mucha plata y hoy día el/ el gobierno está perdiendo tanta plata/ o sea hay algo que está mal/ mal hecho (MAIIIH178),

(12) entonces lo que nosotros debiéramos hacer como pastoral/ es cada vez que se inicia una reunión/ es qué se yo/ hacer una oración/ 
invitar a los papás a ponerse en el nombre de Dios/ qué sé yo/ de Jesús/ ee citar alguna/ frase de San Pedro de Poveda que es nuestro guía espiritual/ en fin// y y invitarlos a reflexionar respecto de eso (MIIM121),

(13) yo creo que los políticos/en un comienzo cuando se van a elecciones y toda la cuestión/ dicen que los jóvenes aquí/ que entonces esa decepción que hay en los jóvenes se ve reflejada en que los jóvenes no quieran votar/ no quieran hacer nada/y aparte que hoy en día la política es cada vez más corrupta// sea de un partido o de otro// cual de todos los políticos es más corrupto/ entonces si uno no va a vivir de la política/ es mejor que se chante y filo/ total// el que quiera inscribirse que se inscriba/ y bien/ si cada uno ve como quiere expresar sus ideas ante el gobierno/ o la política (MIM108),

(14) yo creo que un buen amigo es el que/ logra el que logra alegrarse con lo cuando tú le cuentas algo// que/ que/ te pasa/qué sé yo/ y cuando también siente empatía cuando tú estás triste/ en definitiva es como cuando le importan/ las cosas que a ti te pasan (MIIM121),

(15) ellos estuvieron en la casa con la orquesta/ entonces fue como "jay la media fiesta!" / si lo único que nos embarró la onda que ese día llovió// y quedó la escoba pero a las finales igual lo pasamos bien (BIIM025),

(16) las campañas electorales son realmente una estupidez absurda que pueden inventar los políticos/ definitivamente una estupidez porque en vez de ver solución a los problemas/ hacen más conflicto para tratar de alzar más su puesto y al final y al cabo nunca arreglan progresivamente la vida que estamos llevando po (BIH002),

(17) se puede decir que me gustaba la ideología y me dejé guiar su cierto tiempo por ellos/ pero al final al cabo me di cuenta que no era lo mío ¿cachái? (BIH002),

(18) la verdad es que// estái tan poco tiempo ahí/ que a la final te da lo mismo porque/ tu casa a la final es el dormitorio/ tú llegas a tu casa a dormir/ y después sales temprano en la mañana a trabajar (MBIIH065),

(19) generalmente te va a contratar una empresa como fabricante de como co una una empre/ una fábrica de muebles te va a contratar/ entonces te van a pagar en la medida que vendas/ entonces al final de cuentas/ esas son las expectativas las expectativas siempre/ mías fueron que el sueldo me lo tenía que hacer yo (MAIIIM185),

(20) llegué así/ y puta/ enojado/ ¿cachái?/ porque con mi señora/ puta/ la camioneta al lado ¿cachái? / acelerando/ le dije "ten cuidado po/ conchetumadre" ¡oh! ¿cachái?/ y llegué y lo pasé/ después al tiro me pilló como dos semáforos más allá/ se me ganó al lado y me 
dijo "¡ah!/ ¿te creí muy chorito?/ ¡qué soi prepotente"/ yo le dije "bueno/ ¿y qué conchetumadre?/ ¿qué? ¿te vai a parar?" / cuento corto/ apagué la moto/ le puse la pata/ me bajé/ le puse una patada en la puerta/ me subí a la moto y apreté cueva (MBIH051),

(21) EM que es como la cara clásica del dominio de la derecha económica ee chilena/ LT que también es un diario de corte liberal también pro empresarial y el resto de la prensa en un// de que no existe/ o sea o es la prensa del gobierno que es LN que trata de ser crítico pero a fin de cuentas dice lo que el gobierno quiere/ TC que también a estas alturas del partido lo único que hace es prácticamente se centró como un medio de comunicación netamente ee $\mathrm{mm}$ casi de corte oficialista (MAIH145),

(22) yo creo que no debería existir el aborto/ porque ya si/ puta/ no querí no quieres o no puedes en muchos casos o en el caso soy soy/ bueno siendo mujer ultrajada y de eso nace un hijo/ al fin y al cabo es una vida y si ya no la quieres tener por último dala en adopción (BIH002),

(23) las dos sí a la final y al cabo son fiestas/ las tení que pasar bien nomás/ es que hay que reírse sacar las penas ya que ya se va el año empezái año nuevo/ entonces hay que pa/ pasarla bien po en familia (BIH002),

(24) yo andaba con mis dos hijos/ solo/ y supe que le llamó mucho la atención que yo me preocupara de mis hijos/ las comidas que ee todo lo que se relacionara con ee las vacaciones// perte/ pertenecimos a la misma alianza// en resumen/ llegué de vuelta a Santiago// y ella le redactó la carta al prorrector/ y y me gané al final la beca del cincuenta por ciento (MAIIIH180).

3) De distanciamiento: introducen un miembro discursivo que relativiza o resta validez al contenido expresado anteriormente, resaltando que es el nuevo segmento el que resulta pertinente en la interpretación de lo dicho por el hablante. Los reformuladores que cumplieron la función de distanciamiento, en nuestros materiales, fueron igual, en todo caso y de todas maneras.

De distanciamiento: relativizan

$$
\mathrm{A} \leftarrow \mathrm{A} / \mathrm{B}
$$

Ejemplos:

(25) aunque sean los chiquillos ya grandes pero igual para nosotros la navidad es como bien es como familiar así/ aunque los niños estén grandes igual le colocamos su regalito que a veces usted sabe que depende la situación/ hay años que uno está mejor otros está peor 
pero igual ahí no falta/ su regalito y los cuatro/ ya después si ellos quieren salen qué sé yo/ pero siempre hemos estado juntos siempre siempre (MIIIM137),

(26) a nosotros igual no nos ha cagado todo eso del Transantiago porque vivimos al lado del metro/ pero el metro se echó a perder/ o sea/ ya no te podí subir al metro porque puros flaites/ está lleno/ no/ horrible/ y yo a veces/ así como para no irme en metro/ me voy caminando para la $\mathrm{u} / \mathrm{y} / \mathrm{mira} /$ igual encuentro que el sistema de la tarjeta igual es bueno/ lo de la tarjeta bip me gusta/ pero los recorridos/ no/ penca/ no me gusta/ y el día en que ya no corra la cuestión de que te vale por dos horas el pasaje/ va a quedar la cagada// las micros no pasan nunca/ los fines de semana o te subí al metro o te subí al metro porque no tení otra opción y yo que igual tengo que ir a trabajar allá/ de repente a partes que no hay metro/ igual es complicado (MIM107),

(27) es raro/ porque no es que me cueste hacer amigos/ pero no todo como que/ no todos son verdaderamente amigos/ y sí creo en todo caso/ que la amistad es fundamental/ para vivir (MAIH146),

(28) a ella le ha tocado la mayor parte hacerse cargo de la M/ lo que / bueno estar con ella durante el día/ y todo lo que eso implica po/ alimentarla/ cambiarle los pañales/ etcétera/ eso también lo hago cuando tengo tiempo/ pero eso es/ mucho menos/ evidentemente/ $\mathrm{mm}$ / y no sé/ yo no sé si eso estará bien o mal aa/ ee/ hay opiniones de todo tipo/ de todo tipo/ yo creo de todas maneras que para el padre/ y esta es mi opinión digamos/ que para el padre/ para el hombre digamos/ es más fácil después relacionarse con los hijos (MIH101).

4) Rectificativos: introducen un segmento de discurso que corrige una información dicha con anterioridad, debido a que no resulta satisfactoria para el hablante. Los marcadores rectificativos relevados en el corpus, ordenados de modo decreciente, fueron o sea, bueno, digo, digamos, miento, más bien, perdón y es decir.

$$
\begin{gathered}
\text { Rectificativos: corrigen } \\
\mathrm{A} \leftarrow \sim \mathrm{A} / \mathrm{B}
\end{gathered}
$$

Ejemplos:

(29) entonces después ya llega un momento/ de que uno quisiera estar más tranquila y a mí/ mi sueño/ cuando yo jubile/ porque yo quiero jubilar luego/ anticipado// y mi marido igual porque nosotros como gente empezamos a a estudiar/ o sea a trabajar muy jóvenes/ entonces ya estamos cansados (MIIIM137), 
(30) una vez que/ yo no estaba pero fuimos a Rapel/ o sea fueron a Rapel y era como de las primeras veces que $\mathrm{G}$ presentaba a $\mathrm{P}$ ante su familia (MAIH148),

(31) me llego a emocionar cuando me acuerdo// pero no tengo bonitos recuerdos de eso entonces después yo me casé/ bueno estudié/ me casé/ tengo mi marido (MIIIM137),

(32) E: ee ¿tú viste el el reality show de Canal 13 "Amor ciego"? I: no/ casi nada/ pero sí sabía de qué se trataba/ porque en la casa más de alguien lo veía E: ¿y qué te pareció este programa/ en general? I: pero ese lo vi po/ el segundo no lo vi/ a lo/digo/ el primero sí/ no/ el primero lo vi/ el segundo no lo vi (MIIM123),

(33) fue elegido el mejor ee ee ee profesional de la promoción/ y no solamente la promoción sino que de ee/ fue elegido el mejor alumno que egresaba de la universidad donde él estudió y/ por lo tanto también recibió hartos aplausos/ digamos hartos hartos premios (MAIIIH179),

(34) y el día lunes en la noche/ me voy a acostar/ fui al colegio y todo/ y el día lunes en la noche/ ya me voy a acostar// llego del colegio/ no/ miento/ no estaba en el colegio/ estaba estaba trabajando ya en la papelera/ y// y mi hermano estaba en el colegio/ entonces el día martes yo tenía que/ yo entraba a las ocho a la papelera (MBIH053),

(35) yo creo que está mal enfocada// ee o sea/ no es que esté mal enfocada sino más bien yo creo que/ que el currículum que es en definitiva lo que guía el el lo que/ lo que los niños tienen que aprender en la escuela// está muy centrado en los contenidos (MIIM121),

(36) entonces es re divertido porque la directiva de las niñas son las niñas de diez/ no/ desde kin de pre kin/ perdón desde primer/ hasta sexto/ entonces las chiquititas de primero json tan divertidas! (MAIIM172),

(37) tenía alergia a los medicamentos/ es decir/ no tenía alergia a los medicamentos/ tenía una una etapa de mi vida/ de de chico que me me daba una cuestión/ que después descubrieron que se llamaba edema de glotis (MAIIH162).

Por otro lado, como es sabido, en la bibliografía sobre la reformulación como procedimiento discursivo suele distinguirse entre la reformulación parafrástica, en la que se plantea una equiparación semántica y pragmática entre los segmentos reformulado y reformulador, y la no parafrástica, en la que se propone un distanciamiento de diferente grado entre ambos segmentos. A pesar de que no existe un acuerdo general sobre el modo en que esta distinción se aplica a los diferentes tipos de marcadores de reformula- 
ción, a partir del análisis de nuestros materiales, hemos podido determinar que existe una gradación en distintos niveles de paráfrasis de los marcadores relevados. Por consiguiente, proponemos la existencia de una escala o continuo de paráfrasis en los marcadores de reformulación del corpus. En la Tabla 3, se presenta e ilustra la escala o continuo parafrástico comprobado en nuestro análisis de los marcadores de reformulación. Para facilitar su comprensión, también hemos incluido un esquema aclaratorio que representa el movimiento retroactivo subyacente en cada nivel.

TABLA 3. Escala o continuo de variantes generales de marcadores de reformulación

\begin{tabular}{|c|}
\hline + Parafrástico \\
\hline 1. Explicativos \\
A1, o sea A2 \\
$+/-$ Parafrástico \\
\hline A1, A2 y A3, al fin y al cabo A4 \\
\hline +/ - No parafrástico \\
\hline A. De distanciamiento todas maneras B \\
\hline + No parafrástico \\
\hline A, mejor dicho B
\end{tabular}

Como se aprecia en la Tabla 3, el nivel de paráfrasis plena lo asumen los marcadores explicativos, que plantean una equivalencia semántica completa entre los segmentos vinculados. Luego se encuentran los marcadores recapitulativos que son más o menos parafrásticos, ya que pueden asumir una orientación argumentativa equivalente o contraria entre los segmentos, si bien su función elemental es sintetizar el contenido semántico de los miembros discursivos precedentes en uno solo. Posteriormente, están los marcadores de distanciamiento que son más o menos no parafrásticos, puesto que sin dejar de reconocer que el segmento reformulado es cierto, anulan su validez para resaltar la pertinencia del segmento reformulador. Finalmente, los marcadores rectificativos implican un nivel plenamente no 
parafrástico, ya que invalidan al segmento anterior mediante el siguiente. A nuestro juicio, este último nivel sigue consistiendo en una reformulación debido a que -de todas formas- se verifica un movimiento retroactivo en el discurso, mediante el cual los hablantes intentan reparar posibles fallos en la comprensión del interlocutor. En este sentido, la reformulación puede ir desde la explicación hasta la rectificación (Portolés, 2001), lo que sugiere que la reformulación adopta, bajo la forma de la rectificación, su forma más compleja y, por consiguiente, la manera más inusual de manifestarse en el discurso (cf. Rojas et al., 2012).

\subsection{Análisis sociolingüistico de los marcadores de reformulación relevados en el corpus}

En esta sección, se exponen los resultados de nuestro estudio con respecto a la relación entre la frecuencia de empleo de los tipos generales de marcadores de reformulación y de los reformuladores específicos más frecuentes con las tres variables extralingüísticas consideradas en el análisis: sexo, edad y grupo socioeconómico de los sujetos de la muestra ${ }^{15}$.

\subsubsection{Sexo}

En la Tabla 4 y el Gráfico 2 presentamos las frecuencias absoluta y porcentual de la ocurrencia de los tipos generales de marcadores de reformulación identificados en el corpus, de acuerdo con el sexo de los sujetos.

TABLA 4. Frecuencia absoluta y porcentaje de los tipos de marcadores de reformulación relevados en el corpus según el sexo de los sujetos de la muestra

\begin{tabular}{|c|c|c|c|c|c|}
\hline Sexo & Explicativos & Recapitulativos & Distanciamiento & Rectificativos & Totales \\
\hline Hombres & $1181(54,4)$ & $215(9,9)$ & $659(30,4)$ & $115(5,3)$ & $2170(100)$ \\
\hline Mujeres & $1222(54,1)$ & $197(8,7)$ & $697(30,9)$ & $141(6,3)$ & $2257(100)$ \\
\hline
\end{tabular}

${ }^{15}$ Cabe destacar que, en contraste con los resultados informados en Rojas et al. (2012), en este estudio no solo hemos aumentado de modo considerable la cantidad de entrevistas que analizamos (120 frente a 72), sino que también hemos incorporado la aplicación de pruebas estadísticas inferenciales, a fin de medir la significación estadística de nuestros resultados, además de informar frecuencias absolutas y porcentuales (cf. 2.4). 
Gráfico 2. Porcentaje de frecuencia de los tipos de marcadores de reformulación en el corpus según el sexo de los sujetos de la muestra

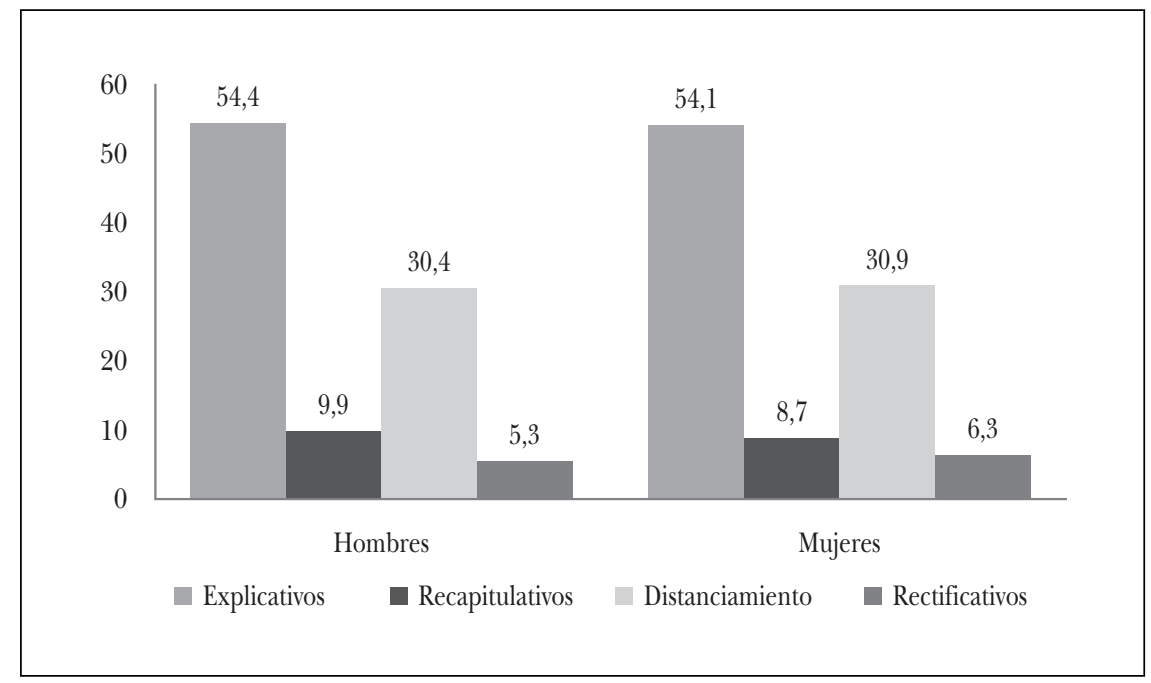

De acuerdo con los datos precedentes, en términos estadísticos descriptivos la ocurrencia de los tipos generales de marcadores de reformulación no manifiesta diferencias porcentuales importantes entre los hombres y las mujeres, si bien estas últimas superan -levemente- a los primeros en el empleo de los reformuladores rectificativos. Solo en el caso de los reformuladores recapitulativos los hombres aventajan a las mujeres, aunque en muy pocas décimas porcentuales.

Por su parte, en la Tabla 5, se indican los resultados de la aplicación de las pruebas paramétrica y no paramétrica, según el sexo de los hablantes, para los tipos generales de marcador de reformulación.

TABLA 5. Resultados de las pruebas ANOVA y de Kruskal-Wallis según tipos de marcador de reformulación y sexo de los sujetos

\begin{tabular}{|l|c|c|c|c|}
\hline Tipo de marcador de reformulación & $\mathrm{F}$ & $\mathrm{p}$ & $\mathrm{Chi}^{2}$ & $\mathrm{p}$ \\
\hline Explicativos & 0,044 & 0,835 & 0,015 & 0,904 \\
Distanciamiento & 0,044 & 0,834 & 3,751 & 0,053 \\
Recapitulativos & 0,217 & 0,642 & 0,000 & 0,987 \\
Rectificativos & 1,154 & 0,285 & 1,032 & 0,310 \\
\hline
\end{tabular}


En síntesis, ninguno de los contrastes de las medias en el empleo de los tipos de marcadores de reformulación, según el sexo de los sujetos, resultó significativo. Por lo tanto, las diferencias porcentuales señaladas al comienzo de esta sección solo reflejan tendencias en la muestra analizada. Solo en el caso de los reformuladores de distanciamiento podríamos considerar que el resultado de la prueba no paramétrica señala una tendencia, a favor del sexo femenino, que -tal vez- podría confirmarse de aumentar el tamaño de la muestra analizada.

En la Tabla 6, asimismo, se indican los resultados de la aplicación de las pruebas, en referencia a los reformuladores específicos más frecuentes.

TABLA 6. Resultados de las pruebas ANOVA y de Kruskal-Wallis según marcadores de reformulación y sexo de los sujetos

\begin{tabular}{|l|c|c|c|c|}
\hline Marcador de reformulación & $\mathrm{F}$ & $\mathrm{p}$ & $\mathrm{Chi}^{2}$ & $\mathrm{p}$ \\
\hline o sea explicativo & 0,030 & 0,863 & 0,001 & 0,977 \\
igual & 0,039 & 0,843 & 3,891 & 0,049 \\
o sea rectificativo & 1,024 & 0,314 & 1,148 & 0,284 \\
al final & 0,111 & 0,740 & 0,079 & 0,778 \\
o sea recapitulativo & 0,148 & 0,701 & 0,481 & 0,488 \\
digamos explicativo & 0,117 & 0,733 & 0,074 & 0,785 \\
onda & 0,147 & 0,702 & 0,326 & 0,568 \\
en todo caso & 0,588 & 0,445 & 0,010 & 0,919 \\
bueno & 0,537 & 0,465 & 0,260 & 0,610 \\
de todas maneras & 1,169 & 0,282 & 0,404 & 0,525 \\
\hline
\end{tabular}

Como se aprecia en la tabla, solo igual presenta significación estadística en la prueba no paramétrica; no obstante, debido a la discrepancia con la prueba paramétrica preferimos caracterizar dicho resultado como una probable predisposición del empleo de dicho marcador por parte de las mujeres de la muestra.

\subsubsection{Edad}

En la Tabla 7 y el Gráfico 3 presentamos las frecuencias absoluta y porcentual de la ocurrencia de los tipos generales de marcadores de reformulación identificados en el corpus, de acuerdo con la edad de los sujetos. 
TABLA 7. Frecuencia absoluta y porcentaje de los tipos de marcadores de reformulación relevados en el corpus según la edad de los sujetos de la muestra

\begin{tabular}{|l|c|c|c|c|c|}
\hline Edad & Explicativos & Recapitulativos & Distanciamiento & Rectificativos & Totales \\
\hline $20-34$ & $874(44,2)$ & $142(7,2)$ & $851(43)$ & $110(5,6)$ & $1977(100)$ \\
$35-54$ & $816(58,4)$ & $125(8,9)$ & $377(27)$ & $80(5,7)$ & $1398(100)$ \\
50 y más & $713(67,8)$ & $145(13,8)$ & $128(12,1)$ & $66(6,3)$ & $1052(100)$ \\
\hline
\end{tabular}

GRÁFICO 3. Porcentaje de frecuencia de los tipos de marcadores de reformulación en el corpus según la edad de los sujetos de la muestra

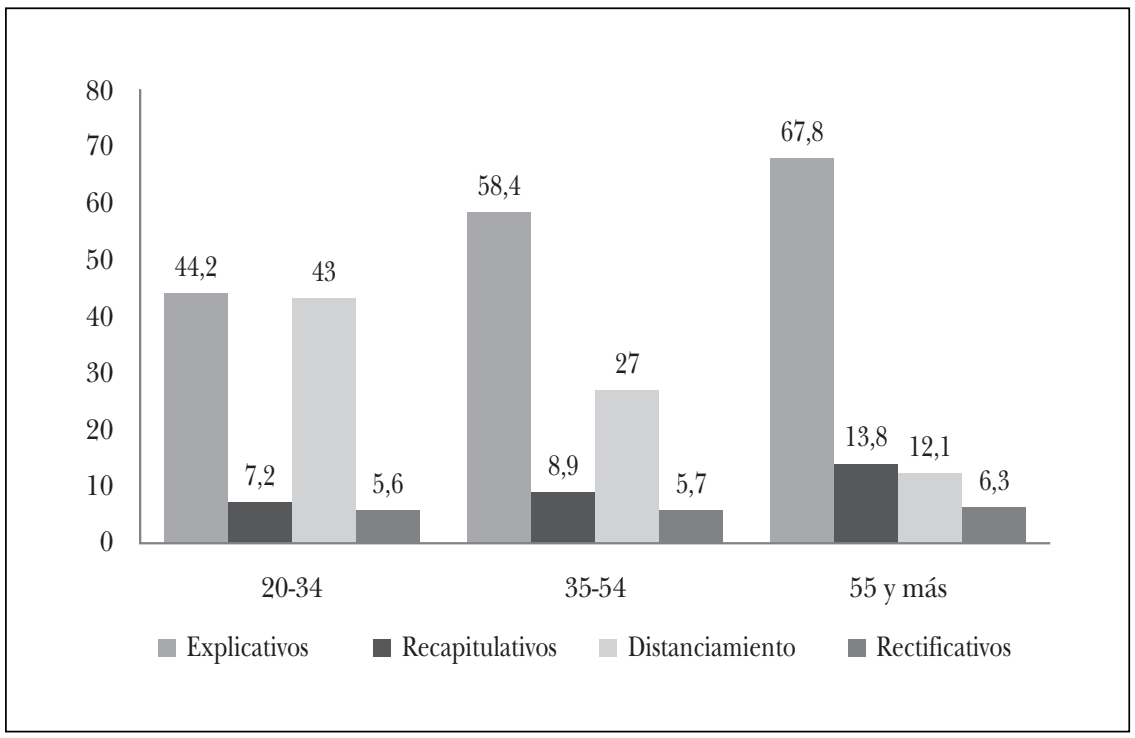

Nuestros resultados muestran que, en términos estadísticos descriptivos, no existen diferencias notables en el empleo de los reformuladores rectificativos, según los diferentes grupos etarios de la muestra, ya que los porcentajes se aproximan bastante. Sin embargo, se advierte un patrón decreciente en el empleo de los reformuladores de distanciamiento, desde un mayor uso en los sujetos jóvenes hasta uno menor en los sujetos de mayor edad. Asimismo, se aprecia un patrón de empleo creciente en los reformuladores explicativos y recapitulativos, con un porciento más bajo en el primer grupo y uno más alto en el tercero. 
La Tabla 8, de modo consecuente, muestra que los resultados de la aplicación de las pruebas paramétrica y no paramétrica, según la edad de los sujetos, son significativos para los reformuladores de distanciamiento, en cuanto tipo de reformulación general.

Los resultados del análisis de las medias correspondientes a la ocurrencia de los marcadores de distanciamiento (prueba paramétrica ANOVA), según el grupo etario de los sujetos, se presentan en el Gráfico 4. La me-

TABLA 8. Resultados de las pruebas ANOVA y de Kruskal-Wallis según tipos de marcador de reformulación y edad de los sujetos

\begin{tabular}{|l|r|r|r|c|}
\hline Tipo de marcador de reformulación & F & p & Chi $^{2}$ & $\mathrm{p}$ \\
\hline Explicativos & 0,518 & 0,597 & 3,046 & 0,218 \\
Distanciamiento & 15,482 & 0,000 & 40,954 & 0,000 \\
Recapitulativos & 0,232 & 0,793 & 0,435 & 0,804 \\
Rectificativos & 2,656 & 0,074 & 5,331 & 0,070 \\
\hline
\end{tabular}

GRÁFICO 4. Medias marginales estimadas de reformuladores de distanciamiento según edad

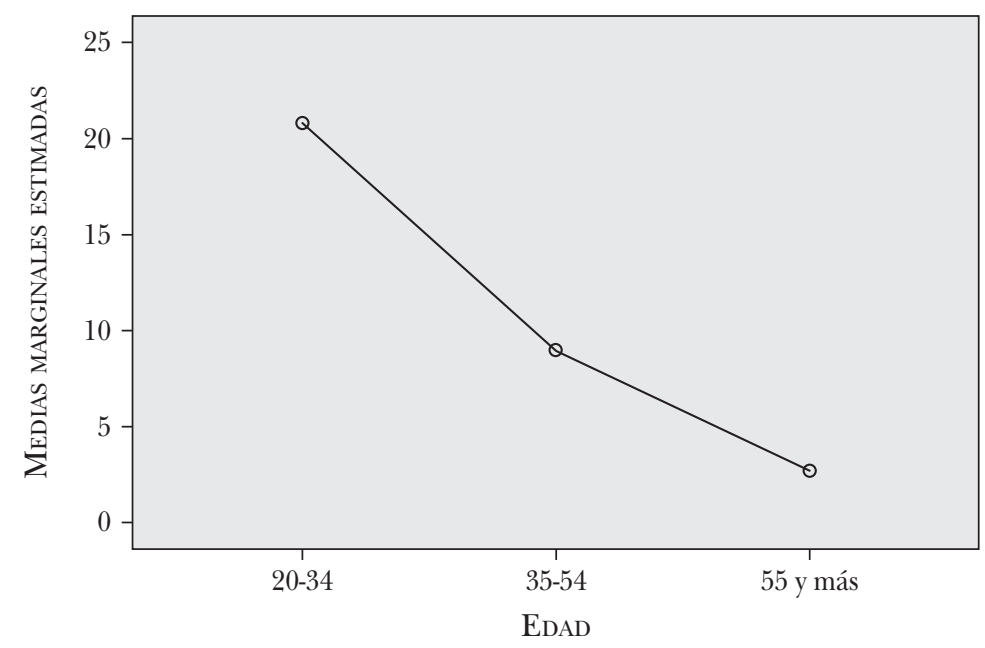


dia para el primer grupo (20-34 años) es de 21,275, mientras que para el segundo (35-54), de 9,425 y para el tercero (55 y más), de 3,200. Como se ve, son medias bastante diferentes, verificándose un patrón decreciente con una media más acusada en el grupo más joven de la muestra y un empleo de marcadores de distanciamiento claramente menor en el grupo más viejo.

La prueba no paramétrica (Anova de Kruskal-Wallis), a su vez, da los siguientes rangos promedio de empleo de los reformuladores de distanciamiento y la edad de los sujetos: 20-34 $(85,21)$, 35-54 $(60,71)$ y 55 y más $(35,58)$.

La Tabla 9, por su lado, indica que los resultados de la aplicación de dichas pruebas son significativos para los marcadores de reformulación específicos igual, o sea rectificativo, digamos explicativo y onda.

TABLA 9. Resultados de las pruebas ANOVA y de Kruskal-Wallis según marcadores de reformulación y edad de los sujetos

\begin{tabular}{|l|r|r|r|r|}
\hline Marcador de reformulación & $\mathrm{F}$ & $\mathrm{p}$ & $\mathrm{Chi}^{2}$ & $\mathrm{p}$ \\
\hline o sea explicativo & 0,755 & 0,472 & 4,223 & 0,121 \\
igual & 15,567 & 0,000 & 42,851 & 0,000 \\
o sea rectificativo & 3,438 & 0,035 & 6,847 & 0,033 \\
al final & 0,488 & 0,615 & 4,007 & 0,135 \\
o sea recapitulativo & 0,459 & 0,633 & 0,709 & 0,701 \\
digamos explicativo & 3,301 & 0,040 & 8,427 & 0,015 \\
onda & 8,146 & 0,000 & 20,730 & 0,000 \\
en todo caso & 0,145 & 0,865 & 0,359 & 0,836 \\
bueno & 0,795 & 0,454 & 4,388 & 0,111 \\
de todas maneras & 0,506 & 0,604 & 1,670 & 0,434 \\
\hline
\end{tabular}

Los Gráficos 5 a 7 presentan los resultados de la comparación entre medias de los reformuladores igual, o sea rectificativo y onda, que son más empleados por los sujetos jóvenes de la población en estudio. Por último, el Gráfico 8 muestra el análisis de varianza del reformulador explicativo digamos, cuyo uso es más frecuente entre los hablantes de mayor edad en la misma comunidad. 
GRÁFICO 5. Medias marginales estimadas de igual según edad

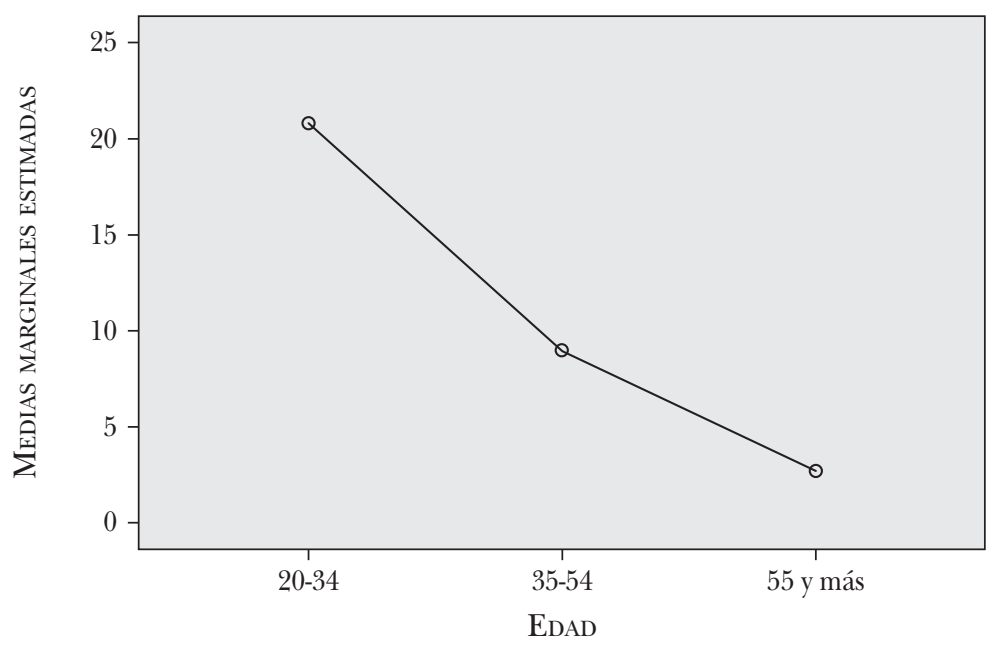

GRÁFICO 6. Medias marginales estimadas

de o sea rectificativo según edad

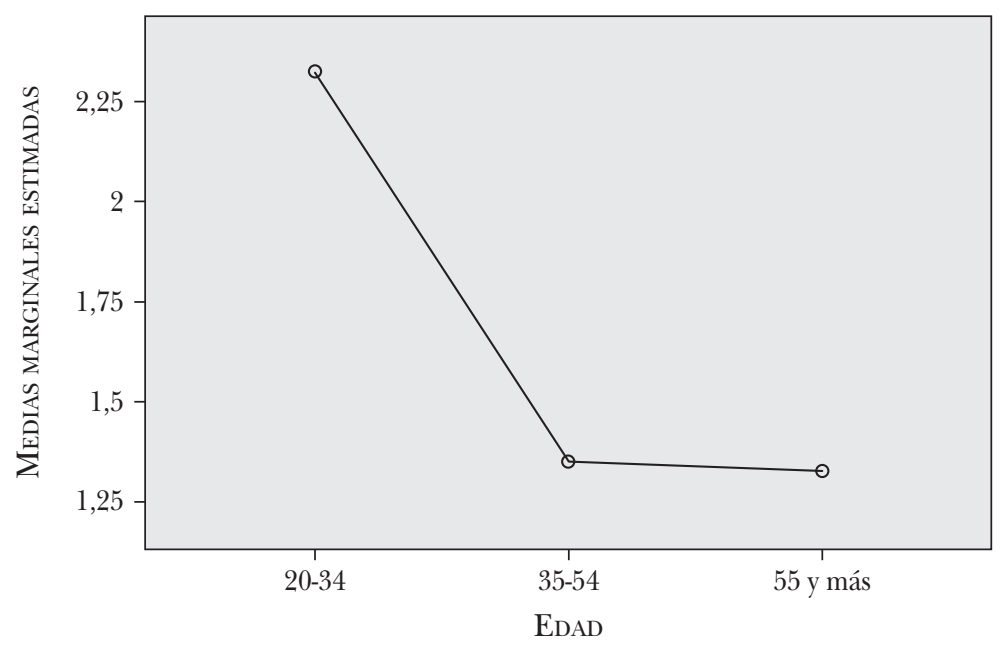


GRÁFICO 7. Medias marginales estimadas de onda según edad

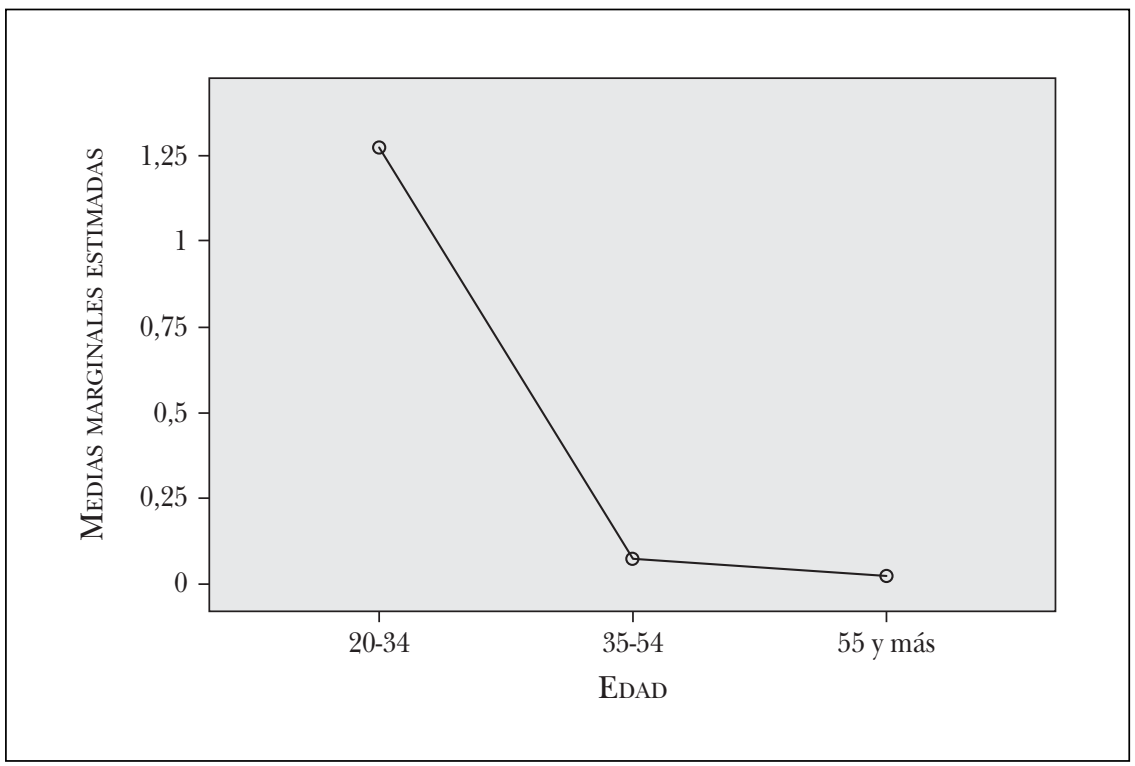

GrÁFICO 8. Medias marginales estimadas

de digamos explicativo según edad

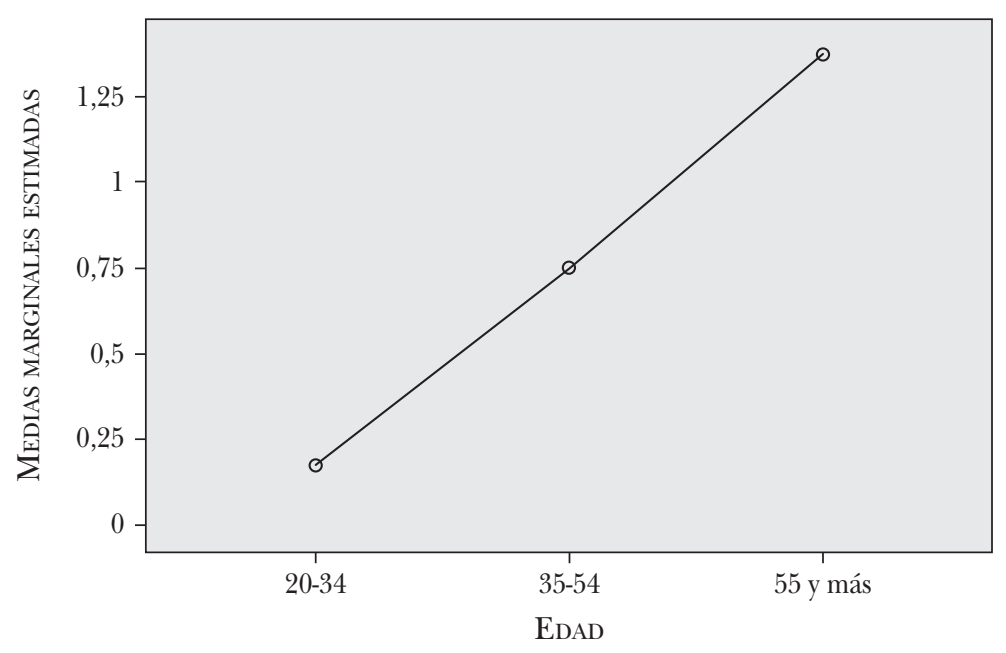




\subsubsection{Grupo socioeconómico}

En la Tabla 10 y el Gráfico 9 presentamos las frecuencias absoluta y porcentual de la ocurrencia de los tipos generales de marcadores de reformulación identificados en el corpus, de acuerdo con el grupo socioeconómico de los sujetos.

Según nuestros datos, en términos estadísticos descriptivos se aprecian claras diferencias en las frecuencias de empleo de los tipos de marcadores

TABLA 10. Frecuencia absoluta y porcentaje de los tipos de marcadores de reformulación relevados en el corpus según el grupo socioeconómico de los sujetos de la muestra

\begin{tabular}{|c|c|c|c|c|c|}
\hline Grupo & Explicativos & Recapitulativos & Distanciamiento & Rectificativos & Totales \\
\hline B & $339(44,1)$ & $84(10,9)$ & $289(37,6)$ & $57(7,4)$ & $769(100)$ \\
MB & $483(42,3)$ & $105(9,2)$ & $502(43,9)$ & $53(4,6)$ & $1143(100)$ \\
M & $642(56,9)$ & $65(5,8)$ & $370(32,8)$ & $51(4,5)$ & $1128(100)$ \\
MA & $939(67,7)$ & $158(11,4)$ & $195(14,1)$ & $95(6,8)$ & $1387(100)$ \\
\hline
\end{tabular}

GRÁfICO 9. Porcentaje de frecuencia de los tipos de marcadores de reformulación en el corpus según el grupo socioeconómico de los sujetos de la muestra

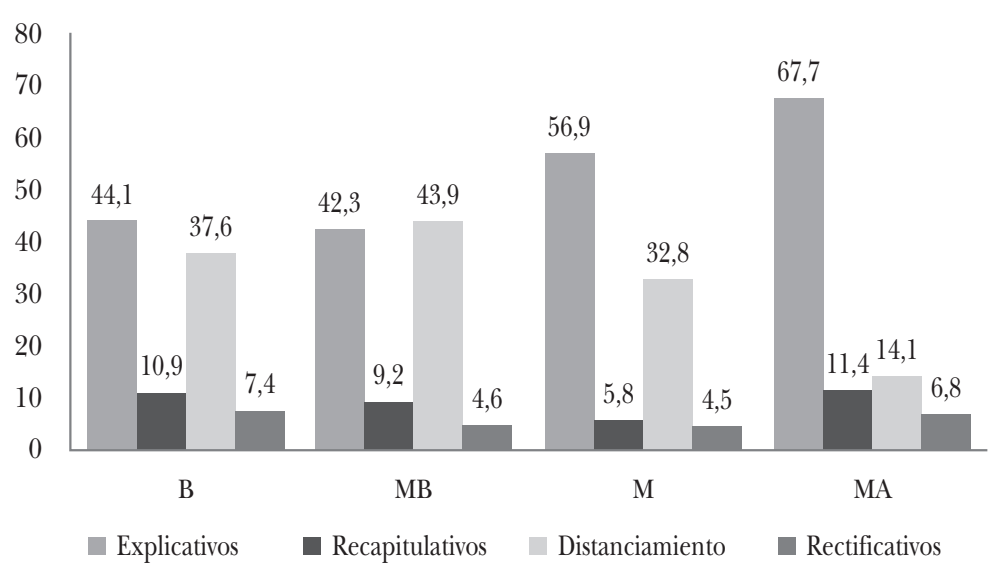


de reformulación generales. En particular, en el caso de los reformuladores explicativos se evidencia un patrón creciente con un porciento más alto en el grupo superior. La frecuencia porcentual de los recapitulativos y los rectificativos, por su parte, muestra una tendencia curvilínea con un mayor empleo en los grupos bajo y medio alto. Los reformuladores de distanciamiento, asimismo, manifiestan un patrón de empleo curvilíneo con una frecuencia de empleo mayor en el grupo medio bajo.

La Tabla 11 muestra que los resultados de la aplicación de las pruebas paramétrica y no paramétrica, de acuerdo con el grupo socioeconómico de los informantes, evidencian significación estadística tanto para los reformuladores explicativos como para los recapitulativos. No obstante, por lo que refiere a los reformuladores rectificativos, los datos de las pruebas no coinciden, por lo que calificaremos este resultado como una tendencia no confirmada.

TABLA 11. Resultados de las pruebas ANOVA y de Kruskal-Wallis según tipos de marcador de reformulación y grupo socioeconómico de los sujetos

\begin{tabular}{|l|r|r|r|r|}
\hline Tipo de marcador de reformulación & $\mathrm{F}$ & $\mathrm{p}$ & $\mathrm{Chi}^{2}$ & $\mathrm{p}$ \\
\hline Explicativos & 8,189 & 0,000 & 26,353 & 0,000 \\
Distanciamiento & 2,143 & 0,099 & 2,752 & 0,431 \\
Recapitulativos & 4,748 & 0,004 & 16,791 & 0,001 \\
Rectificativos & 3,111 & 0,029 & 6,588 & 0,086 \\
\hline
\end{tabular}

La comparación de las medias correspondientes a la frecuencia de los reformuladores explicativos, según el grupo socioeconómico de los sujetos, se expone en el Gráfico 10. La prueba ANOVA proporciona los siguientes resultados: bajo $(11,300)$, medio bajo $(16,100)$, medio $(21,400)$ y medio alto $(31,300)$. Por consiguiente, se muestra una tendencia creciente desde el menor empleo de marcadores explicativos por parte de los sujetos del grupo bajo hacia su mayor frecuencia en los sujetos del medio alto.

La prueba no paramétrica de Kruskal-Wallis señala los siguientes rangos promedio para los grupos de la muestra: bajo $(39,60)$, medio bajo $(51,73)$, medio $(68,00)$ y medio alto $(82,67)$.

Con respecto a la comparación de las medias correspondientes a la ocurrencia de los marcadores de recapitulación, de acuerdo con el factor grupo socioeconómico de los sujetos, el Gráfico 11 muestra los resultados del análisis paramétrico, según el cual las medias para los grupos son bajo $(2,800)$, medio bajo $(3,500)$, medio $(2,167)$ y medio alto $(5,267)$. Como se 
GRÁFICO 10. Medias marginales estimadas de reformuladores explicativos según grupo socioeconómico

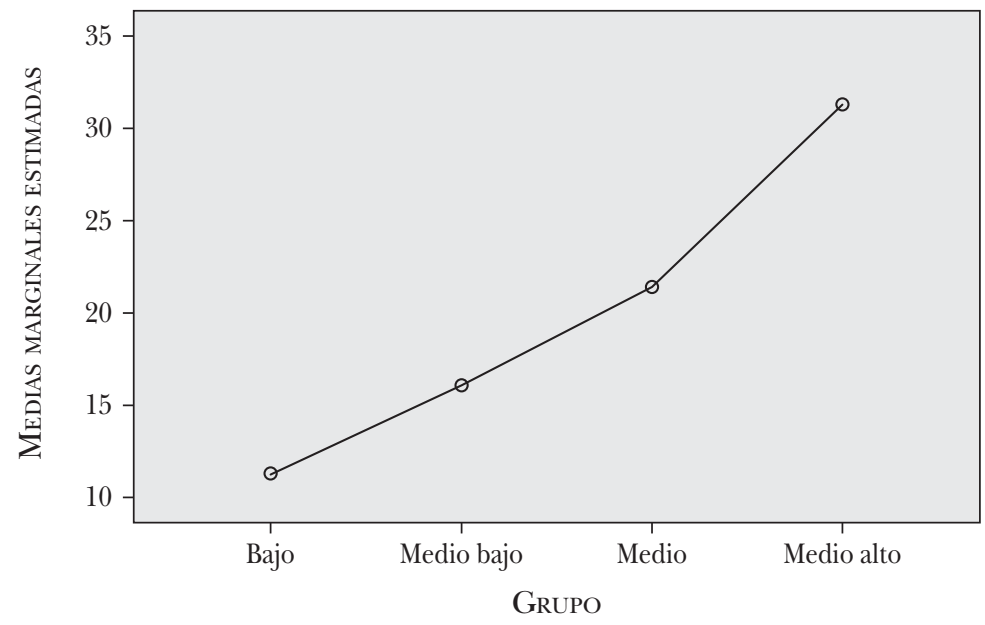

GRÁFICO 11. Medias marginales estimadas de reformuladores recapitulativos según grupo socioeconómico

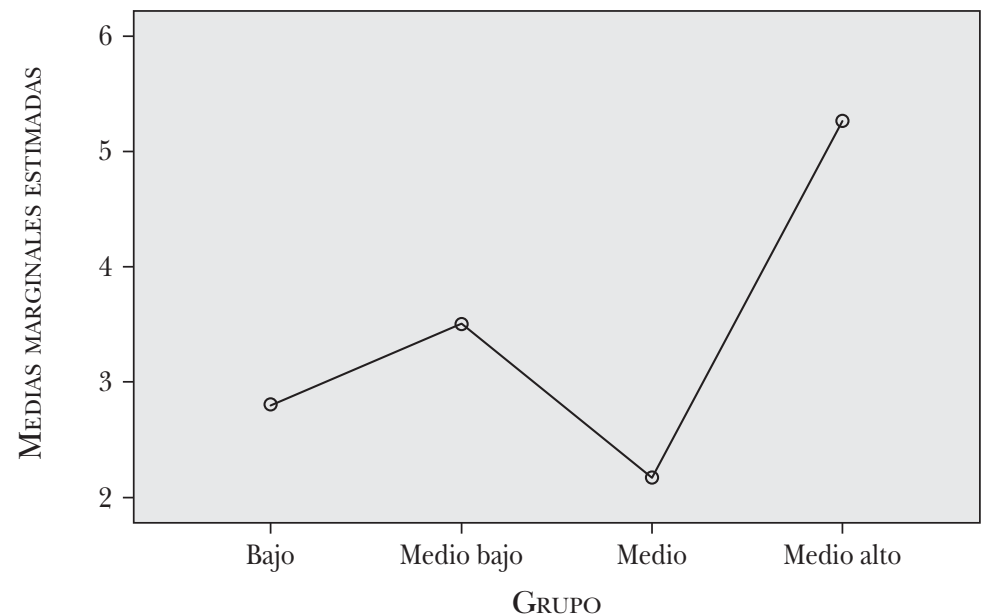


desprende de estos datos, se comprueba un patrón en forma de "ese" con una frecuencia menor en los grupos medio y bajo y con un mayor empleo en los grupos medio alto y medio bajo.

La prueba no paramétrica seleccionada, a su vez, entrega los siguientes rangos promedio para los grupos socioeconómicos de los sujetos: bajo $(50,92)$, medio bajo $(62,40)$, medio $(47,95)$ y medio alto $(80,73)$.

Por su lado, la Tabla 12 señala que ambas pruebas seleccionadas comprueban la significación estadística de las frecuencias de empleo de los siguientes reformuladores específicos: o sea explicativo y recapitulativo, los explicativos digamos y onda y el rectificativo bueno. Sin embargo, con respecto al recapitulativo al final y el reformulador de distanciamiento de todas maneras, los resultados de ambas pruebas no son coincidentes, por lo que -siguiendo la argumentación precedente- solo nos limitaremos a señalar que reflejan tendencias que, tal vez, podrían confirmarse de ampliar los materiales bajo análisis.

TABLA 12. Resultados de las pruebas ANOVA y de Kruskal-Wallis según marcadores de reformulación y grupo socioeconómico de los sujetos

\begin{tabular}{|l|c|c|c|c|}
\hline Marcador de reformulación & $\mathrm{F}$ & $\mathrm{p}$ & \multicolumn{1}{c|}{$\mathrm{Chi}^{2}$} & $\mathrm{p}$ \\
\hline o sea explicativo & 6,319 & 0,001 & 22,632 & 0,000 \\
igual & 2,215 & 0,090 & 2,388 & 0,496 \\
o sea rectificativo & 1,838 & 0,144 & 3,373 & 0,338 \\
al final & 2,489 & 0,064 & 9,502 & 0,023 \\
o sea recapitulativo & 11,130 & 0,000 & 28,187 & 0,000 \\
digamos explicativo & 2,869 & 0,040 & 12,065 & 0,007 \\
onda & 3,719 & 0,013 & 8,080 & 0,044 \\
en todo caso & 0,540 & 0,656 & 2,235 & 0,525 \\
bueno & 4,462 & 0,005 & 13,888 & 0,003 \\
de todas maneras & 2,285 & 0,083 & 10,905 & 0,012 \\
\hline
\end{tabular}

Por otro lado, los Gráficos 12 al 16 presentan los resultados de la prueba de varianza del empleo de los marcadores de reformulación específicos más frecuentes que resultaron con significación estadística, de acuerdo con el grupo socioeconómico de los informantes. En general, se aprecian cur- 
GRÁFICO 12. Medias marginales estimadas de o sea explicativo según grupo socioeconómico

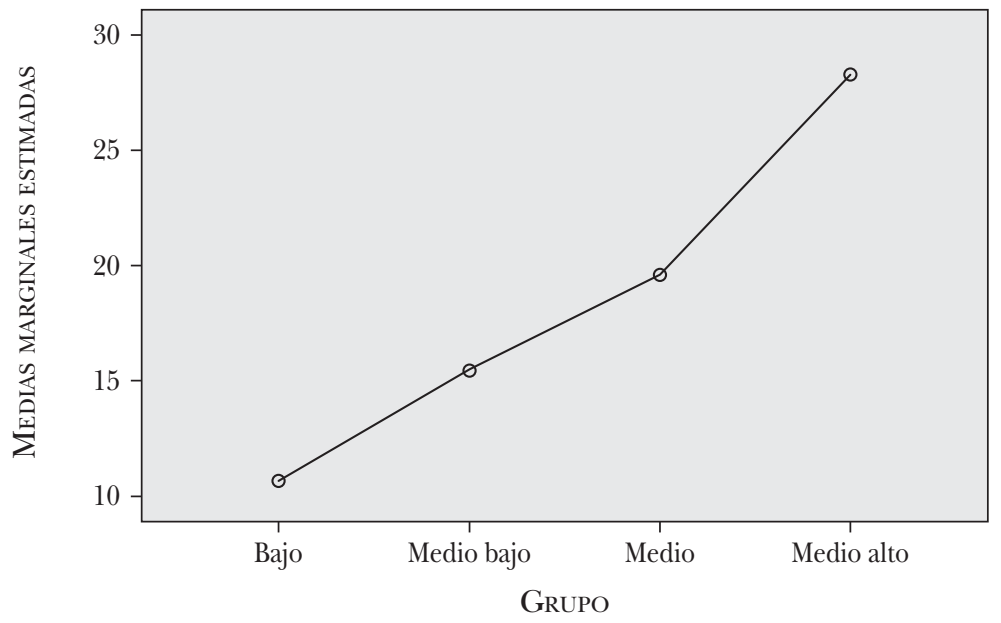

GRÁFICO 13. Medias marginales estimadas de onda según grupo socioeconómico

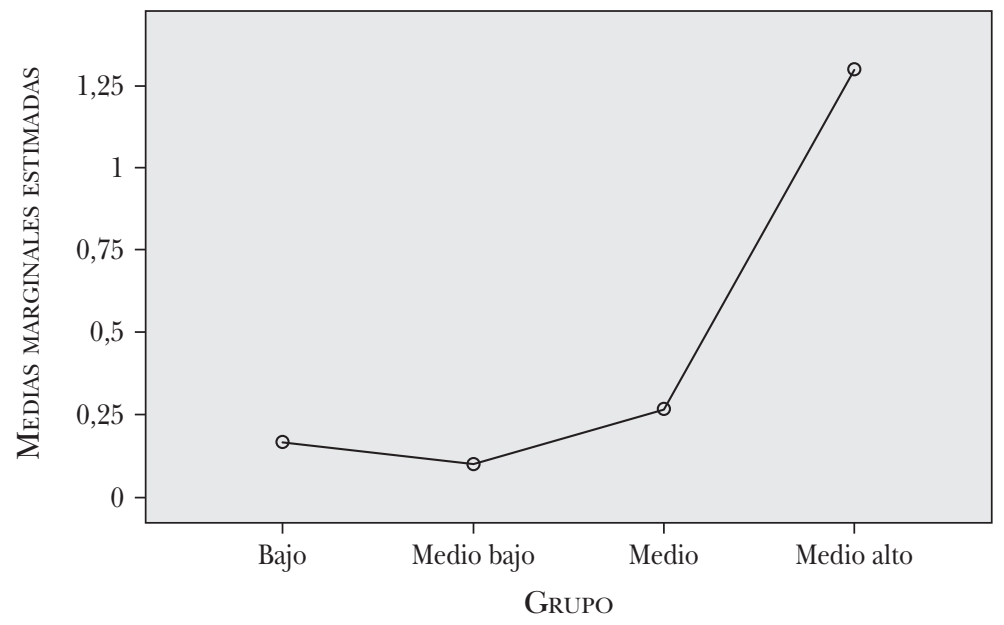


GráFICO 14. Medias marginales estimadas de o sea recapitulativo según grupo socioeconómico

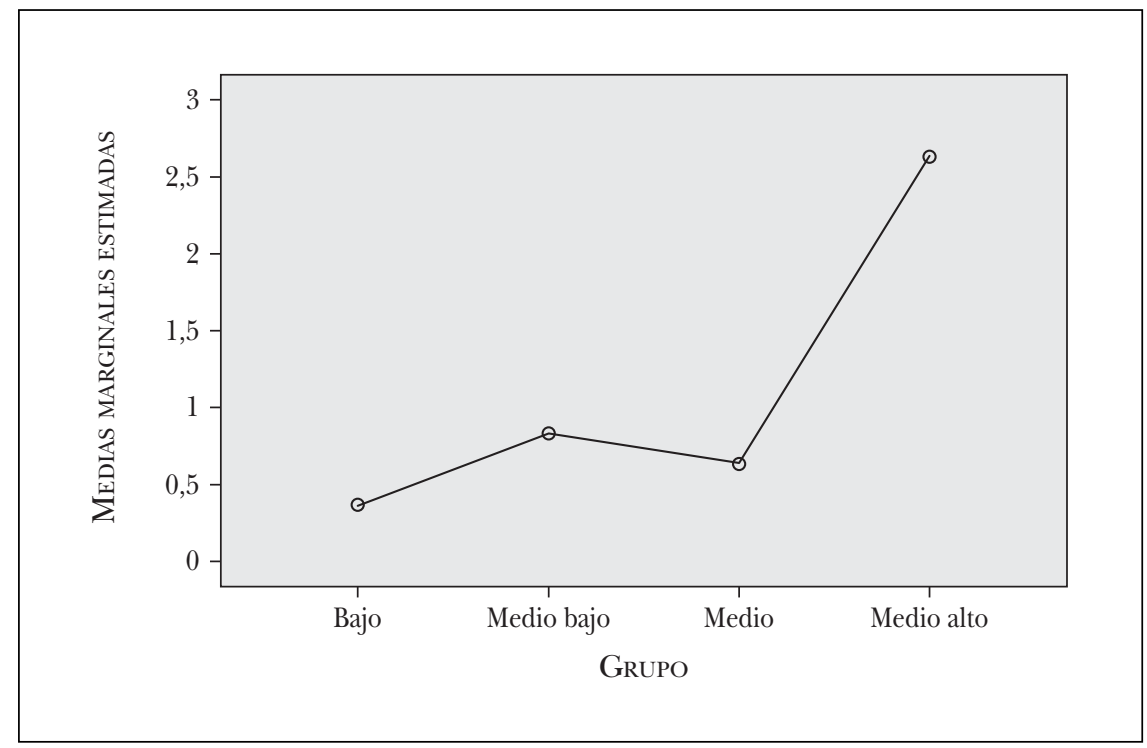

GRÁFICO 15. Medias marginales estimadas de bueno según grupo socioeconómico

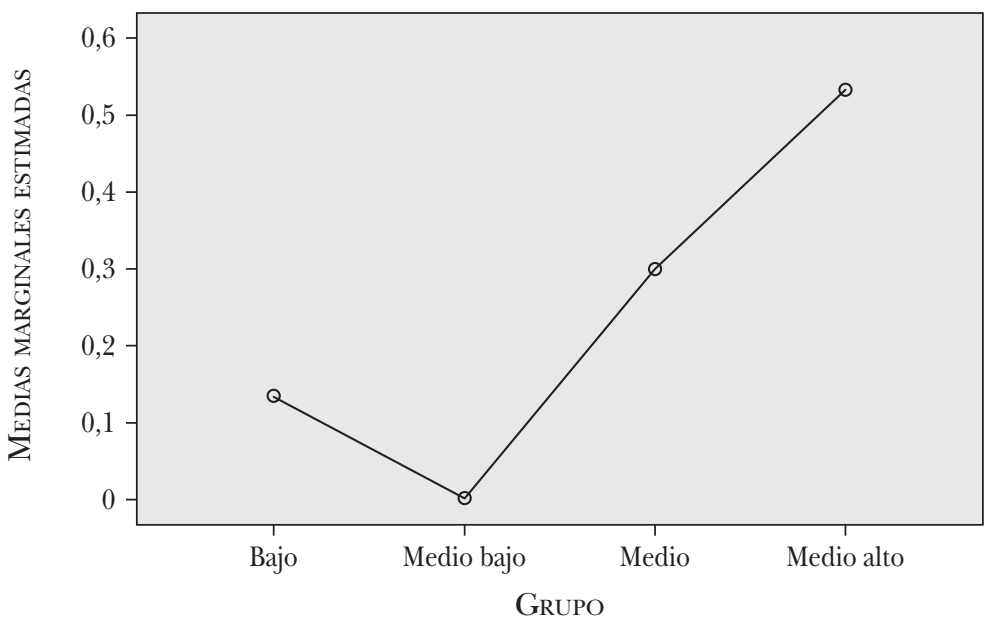


GRÁFICO 16. Medias marginales estimadas de digamos explicativo según grupo socioeconómico

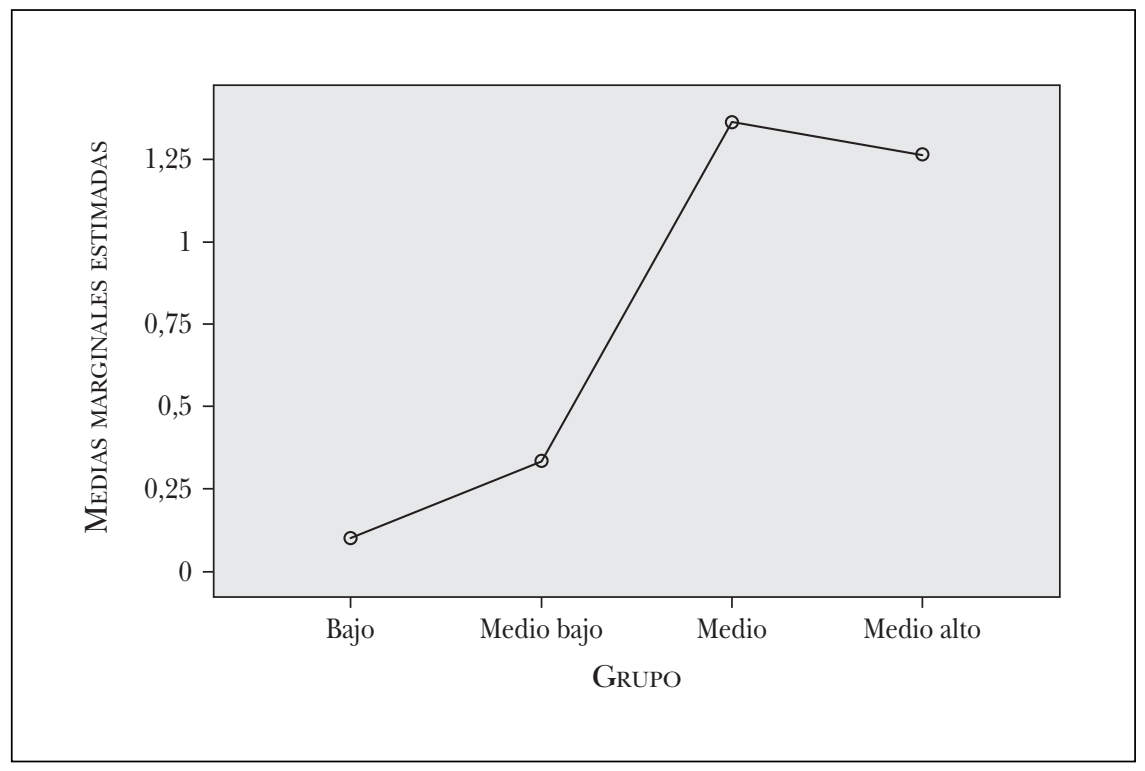

vas de empleo ascendentes, aunque con formas disímiles. De este modo, los sujetos del grupo socioeconómico medio alto de la comunidad en estudio hacen un mayor uso de los marcadores explicativos o sea y onda, así como del recapitulativo o sea y del rectificativo bueno, mientras que los del grupo medio lo hacen del reformulador explicativo digamos, si bien en este último caso la frecuencia de empleo en los hablantes del grupo superior también es alta.

En resumen, por lo que se refiere a la relación entre las características sociodemográficas de los sujetos de la muestra y las diferencias de empleo de los tipos generales de marcadores de reformulación, los resultados de nuestro estudio indican que el grupo socioeconómico es significativo en el caso de los reformuladores explicativos y recapitulativos, mientras que la edad solo lo es en el de los de distanciamiento. El sexo, por su parte, no resultó ser un factor significativo en ninguno de los tipos de marcadores de reformulación. Específicamente, se comprueba una mayor preponderancia del empleo de los reformuladores de distanciamiento por parte de los hablantes jóvenes de la comunidad en estudio, así como un uso mayoritario de reformuladores explicativos y recapitulativos en el discurso de los sujetos del nivel socioeconómico medio alto y, secundariamente, de los recapitulativos en el grupo medio bajo. 


\section{Discusión Y CONCLUSIONES}

En síntesis, nuestro análisis de los tipos de reformulación de un segmento discursivo previo mediante marcadores nos permitió verificar el predominio del empleo, en términos de frecuencia absoluta y porcentual, de los reformuladores explicativos, seguidos de los de distanciamiento, por sobre los recapitulativos y rectificativos, que evidencian frecuencias de uso menores. Por consiguiente, la explicación y el distanciamiento son las funciones predominantes dentro de la reformulación introducida mediante marcadores en la muestra analizada. Por lo que concierne a los marcadores de reformulación más frecuentes, esto es, aquellos sobre los 25 casos, más de la mitad de las ocurrencias corresponde al reformulador explicativo o sea. Le siguen, en importancia, igual como reformulador de distanciamiento, o sea con valor rectificativo, al final y o sea con función recapitulativa, digamos y onda como explicativos, en todo caso y de todas maneras con la función de reformuladores de distanciamiento y, finalmente, bueno como marcador rectificativo. Hemos comprobado, en consecuencia, la ampliación funcional del marcador o sea que, además de desempeñarse como explicativo, puede asumir otros roles dentro de la reformulación, específicamente, los de reformulador recapitulativo y rectificativo. Estos resultados son muy cercanos, en líneas generales, a los que informamos en Rojas et al. (2012). La preponderancia de o sea como reformulador explicativo ha sido destacada también por Martín Zorraquino y Portolés (1999) para el español, en general, y por Valencia (2014b) para los materiales de la norma culta santiaguina, en particular.

En relación con las diferencias de empleo de los tipos generales de marcadores de reformulación, según los rasgos socio-demográficos de los sujetos, los resultados muestran que el sexo no resultó tener significación estadística en ninguno de los tipos de reformulador. Por otra parte, el factor etario fue significativo en el empleo de los reformuladores de distanciamiento, ya que es más característico de los hablantes jóvenes. Finalmente, el grupo socioeconómico es significativo en el caso de los reformuladores explicativos, que son más empleados por los sujetos del grupo medio alto, y en el de los recapitulativos, que son más frecuentes en el grupo medio bajo. Con respecto a los marcadores de reformulación específicos, nuestro análisis también indica que las diferencias de sexo no son significativas. Las diferencias entre los grupos etarios de los hablantes, por su lado, resultaron ser significativas, estadísticamente, solo con respecto a los marcadores explicativos onda y digamos: el primero lo emplean más los informantes más jóvenes, mientras el segundo, los sujetos de mayor edad; asimismo, se verificó la significación del factor etario en el empleo del reformulador de distanciamiento igual y del rectificativo o sea, ya que el empleo de ambos 
marcadores es preponderante entre los hablantes más jóvenes. Por último, las diferencias entre los grupos socioeconómicos son significativas en cuanto al empleo de los marcadores explicativos o sea, onda y digamos, del reformulador recapitulativo o sea y del marcador de rectificación bueno. El empleo de los marcadores antes señalados es más preponderante entre los sujetos del grupo medio alto. De este modo, con base en estas diferencias, hemos podido corroborar la hipótesis de este estudio, esto es, que el influjo de los factores sociodemográficos en el empleo de los marcadores de reformulación es de carácter irregular.

En nuestra opinión, el hecho de que la reformulación explicativa se manifieste con mayor frecuencia en los sujetos del grupo medio alto quizás podría deberse a una característica más elaborada de su discurso, devenida de la necesidad de aclarar más sus puntos de vista o de hacer más explícita la información proporcionada. Al respecto, resulta muy tentador esgrimir como justificación para estas diferencias la incidencia de la distinción entre código elaborado y código restringido de Bernstein (1964); no obstante, son bien conocidas las debilidades de esta teoría, que han sido críticamente presentadas por López Morales (2004: 188-194). En lo concerniente a nuestros datos, nos limitaremos a señalar la posible vinculación entre las necesidades expresivas más complejas y los recursos explicativos en el sociolecto medio alto; aunque, en ningún caso, de esta relación podría desprenderse que se trata de "códigos" diferentes, ni mucho menos que constituyen la manifestación de un "déficit" del sociolecto bajo. Para satisfacer estos requerimientos expresivos más elaborados, los informantes del grupo medio alto recurren con frecuencia a marcadores como o sea, onda y digamos, en especial, el primero, que -como ya señalamos- cumple además las funciones de rectificación y recapitulación.

Por otro lado, es probable que el mayor empleo de los reformuladores de distanciamiento, casi exclusivamente igual, en los sujetos más jóvenes de la muestra se deba a la naturaleza menos asertiva o más titubeante propia de sujetos que aún no han alcanzado una madurez o una estabilidad laboral y socio-afectiva plena. Este aspecto podría justificar el empleo de marcadores cuya función es el distanciamiento mediante la anulación de la pertinencia del segmento discursivo previo; propiedad que implica que los hablantes estén continuamente relativizando las ideas expresadas con anterioridad. Tal vez, podría plantearse que existe una asociación entre el empleo frecuente de los reformuladores de distanciamiento con ciertos rasgos característicos de los hablantes de español en Chile, tales como cierto grado de inseguridad o de relativismo argumentativo manifestado, de modo lingüístico-discursivo, en lo principal, mediante el empleo de dichos marcadores (Rojas et al., 2012). Asimismo, la extensión del uso de igual como reformulador de distanciamiento, en especial, en el habla de los sujetos más 
jóvenes de la muestra (20 y 34 años), probablemente, podría interpretarse como un proceso de cambio lingüístico en curso, en el cual dicho marcador parece estar desplazando a otras partículas (de todas maneras y en todo caso) que cumplen la misma función (San Martín, 2004-2005 y 2013).

Para finalizar, quisiéramos insistir en la utilidad de llevar a cabo trabajos contrastivos con muestras de otras comunidades de habla española, que replicaran lo desarrollado en el presente estudio, de manera de comparar el comportamiento de los marcadores de reformulación en otras variedades del español oral, contribuyendo, en general, al conocimiento de la variación socio-dialectal del empleo de este tipo de partícula en la lengua española. Asimismo, el desarrollo de una línea de investigación como la que aquí perfilamos aportaría información de interés para la caracterización del empleo de los marcadores del discurso en la modalidad oral de nuestra lengua, en contraste con la escrita, así como para la contrastación empírica de las categorizaciones de partículas propuestas, en términos teóricos. 


\section{BIBLIOGRAFÍA}

ADIMARK (Investigaciones de Mercado y de Opinión Pública) (2003): "Mapa socioeconómico de Chile. Nivel socioeconómico de los hogares del país basado en datos del Censo" [en línea] <http://www.adimark.cl/medios/estudios/ mapa_socioeconomico_de_chile.pdf $>$.

AIM (Asociación de Investigadores de Mercado) (2008): "Grupos socioeconómicos 2008” [en línea] <http://www.anda.cl/estudios/textos/DescripcionGSE Chile2008.pdf $>$.

Anscombre, J. y Ducrot, O. (1994): La Argumentación en la lengua, Madrid, Gredos.

BERNSTEIN, B. (1964): "Elaborated and restricted codes: their social origins and some consequences", en J. Gumperz y D. Hymes (eds.), The Etnography of Communication. American Anthropologist, 66 (6, Parte 2), págs. 55-69.

Blas Arroyo, J. L. (2005): Sociolingüistica del español. Desarrollos y perspectivas en el estudio de la lengua española en contexto social, Madrid, Cátedra.

Blakemore, D. (1993): "The relevance of reformulations", Language and Literature, 2 (2), págs. 101-120.

BRIGHT, W. (1998): "Social factors in language change", en F. Coulmas (ed.), The Handbook of Sociolinguistics, Oxford, Blackwell, págs. 81-91.

Carbonero, P. y Santana, J. (2010): "Marcadores del discurso, variación dialectal y variación social”, en Ó. Loureda y E. Acín (coords.), Los estudios sobre marcadores del discurso en español, hoy, Madrid, Arco/Libros, págs. 497-521.

Casado Velarde, M. (1991): "Los operadores discursivos es decir, esto es, o sea y a saber en español actual: valores de lengua y funciones textuales”, Lingüistica Española Actual, 13, págs. 87-116.

CORTÉs, L. (1998): "Marcadores del discurso y análisis cuantitativo", en M. Martín Zorraquino y E. Montolío (coords.), Los marcadores del discurso. Teoría y análisis, Madrid, Arco/Libros, págs. 143-160.

CORTÉs, L. y CAMACHO, M. (2005): Unidades de segmentación y marcadores del discurso, Madrid, Arco/Libros.

CuencA, M. J. (2003): "Two ways to reformulate: a contrastive analysis of reformulation markers", Journal of Pragmatics, 35, págs. 1069-1093.

FANT, L. (2011): "Modalización discursiva en el diálogo oral" en L. Fant y A. M. Harvey (eds.), El diálogo oral en el mundo hispanohablante. Estudios teóricos y aplicados, Madrid/Frankfurt, Iberoamericana/Vervuert, págs. 119-138.

Fuentes, C. (2009): Diccionario de conectores y operadores del español, Madrid, Arco/ Libros.

GARCÉs Gómez, M. P. (2003): "Los marcadores de recapitulación y de reconsideración en el discurso", Revista de Investigación Lingüistica, 1 (6), págs. 111-141.

- (2005): "Reformulación y marcadores de reformulación", en M. Casado, R. González y Ó. Loureda (eds.), Estudios sobre lo metalingüistico (en español), Frankfurt, Peter Lang, págs. 47-66. 
- (2008): La organización del discurso: marcadores de ordenación y reformulación, Madrid/Frankfurt, Iberoamericana/Vervuert.

- (2010): "Marcadores de corrección y rectificación en los textos escritos", Revista de Investigación Lingüistica, 13, págs. 87-105.

- (2011): "Procesos de reformulación en el discurso oral: corrección y rectificación”, Español Actual, 96, págs. 89-106.

García Negroni, M. y Marcovecchio, A. (2013): "No todo da lo mismo: de la comparación al distanciamiento. El caso de 'igual”, Oralia, 16, págs. 143-162.

GüLICH, E. y Kотschi, T. (1983): "Les marqueurs de reformulation paraphrastique", Cahiers de Linguistique Française, 5, págs. 305-351.

- (1995): "Discourse Production in Oral Communication. A Study Based on French”, en U. Quasthoff (ed.), Aspects of Oral Communication, Berlín, De Gruyter, págs. 30-66.

Hernández CAmpoy, J. M. y Almeida, M. (2005): Metodología de la investigación sociolingüistica, Málaga, Comares.

Hummel, M. (2012): Polifuncionalidad, polisemia y estrategia retórica. Los signos discursivos con base atributiva entre oralidad y escritura, Berlín, De Gruyter.

ICCOM (Instituto Consultor en Comercialización y Mercado) (2005): "Descripción Básica de los Niveles Sociales Hogares Urbanos Región Metropolitana" [en línea] <http://www.cadem.cl/v1/files/estadistico/descripcionBasica_ GSE_ICCOM_2005.pdf $>$.

LABOv, W. (1983): Modelos sociolingüísticos, Madrid, Cátedra.

LAVANDERA, B. (1978): “Where does the sociolinguistic variable stop?”, Language in Society, 7, págs. 171-182.

Lenski, G. (1954): "Status Crystallization: A Non-vertical Dimension of Social Status”, American Sociological Review, 19, págs. 405-413.

López Morales, H. (1994): Métodos de investigación lingüística, Salamanca, Ediciones Colegio de España.

- (2004): Sociolingüística, Madrid, Gredos.

LOUREDA, Ó. (2001): "Del metalenguaje y de sus tipos (con especial referencia al criterio de los modos de significar)”, Quaderni di Semantica, 2 (2), págs. 287-333.

- y Acín, E. (coords.) (2010): Los estudios sobre marcadores del discurso en español, hoy, Madrid, Arco/Libros.

Macaulay, R. (2003): "Discourse variation”, en J. Chambers, P. Trudgill y N. Schilling-Estes (eds.), The Handbook of Language Variation and Change, Oxford, Blackwell, págs. 283-305.

MARTín ZorraQuino, M. (1998): "Los marcadores del discurso desde el punto de vista gramatical”, en M. Martín Zorraquino y E. Montolío (coords.), Los marcadores del discurso. Teoría y análisis, Madrid, Arco/Libros, págs. 19-53.

- y Montolío, E. (coords.) (1998): Los marcadores del discurso. Teoría y análisis, Madrid, Arco/Libros.

- y PORTOLÉs, J. (1999): "Los marcadores del discurso", en I. Bosque y V. Demonte (dirs.), Gramática descriptiva de la lengua española, Madrid, Espasa-Calpe, págs. 4051-4207.

Moreno Fernández, F. (1990): Metodología sociolingüistica, Madrid, Gredos.

- (2009): Principios de sociolingüística y sociología del lenguaje, Barcelona, Ariel. 
PorTolÉs, J. (2001): Marcadores del discurso, Barcelona, Ariel.

- (2004): Pragmática para hispanistas, Madrid, Síntesis.

Prieto, L. (1995-1996): "Análisis sociolingüístico del dequeísmo en el habla de Santiago de Chile”, Boletín de Filología, XXXV, págs. 379-452.

Rojas, C., Rubio, A., SAn Martín, A. y Guerrero, S. (2012): "Análisis pragmático y sociolingüístico del empleo de los marcadores discursivos de reformulación en el habla de Santiago de Chile”, Lenguas Modernas, 40, págs. 103-123.

Rossari, C. (1994): Les operations de reformulation, Berna, Peter Lang.

Roulet, E. (1987): "Complétude interactive et connecteurs reformulatifs", Cahiers de Linguistique Française, 8, págs. 111-140.

SAn Martín, A. (2004-2005): "Igual como marcador discursivo en el habla de Santiago de Chile: función pragmático-discursiva y estratificación social de su empleo", Boletín de Filología, XL, págs. 201-232.

- (2011): "Los marcadores interrogativos de control de contacto en el corpus PRESEEA de Santiago de Chile”, Boletín de Filología, XLV (2), págs. 135-166.

- (2013): "Los reformuladores de distanciamiento en el corpus PRESEEA de Santiago de Chile”, Boletín de Filología, XLVIII (1), págs. 171-199.

- y Guerrero, S. (2015): "Estudio Sociolingüístico del Español de Chile (ESECH): recogida y estratificación del corpus de Santiago”, Boletín de Filología, L (1), págs. 221-247.

Silva-Corvalán, C. (2001): Sociolingüistica y pragmática del español, Washington, Georgetown University Press.

Schiffrin, D. (1987): Discourse Markers, Cambridge, Cambridge University Press.

- (2003): "Discourse Markers: Language, Meaning and Context", en D. Schiffrin, D. Tannen y H. E. Hamilton, The Handbook of Discourse Analysis, Oxford, Blackwell, págs. 54-75.

Serrano, M. J. (2011): Sociolingüística, Barcelona, Ediciones del Serbal.

Trudgill, P. y Hernández Campoy, J. M. (2007): Diccionario de sociolingüistica, Madrid, Gredos.

VAlenCIA, A. (2014a): "Introducción”, Cuadernos de la ALFAL, 5, págs. 4-12.

- (2014b): "Marcadores del discurso en Santiago de Chile", Cuadernos de la ALFAL, 5, págs. 246-276. 